\title{
Idealized model for changes in equilibrium temperature, mixed layer depth, and boundary layer cloud over land in a doubled CO2 climate
}

Article

Published Version

Betts, A. K. and Chiu, J. C. (2010) Idealized model for changes in equilibrium temperature, mixed layer depth, and boundary layer cloud over land in a doubled $\mathrm{CO} 2$ climate. Journal of Geophysical Research, 115 (D19). D19108. ISSN 0148-0227 doi: https://doi.org/10.1029/2009JD012888 Available at https://centaur.reading.ac.uk/16761/

It is advisable to refer to the publisher's version if you intend to cite from the work. See Guidance on citing.

Published version at: http://dx.doi.org/10.1029/2009JD012888

To link to this article DOI: http://dx.doi.org/10.1029/2009JD012888

Publisher: American Geophysical Union

All outputs in CentAUR are protected by Intellectual Property Rights law, including copyright law. Copyright and IPR is retained by the creators or other copyright holders. Terms and conditions for use of this material are defined in the End User Agreement. 


\section{CentAUR}

Central Archive at the University of Reading

Reading's research outputs online 


\title{
Idealized model for changes in equilibrium temperature, mixed layer depth, and boundary layer cloud over land in a doubled $\mathrm{CO}_{2}$ climate
}

\author{
Alan K. Betts ${ }^{1}$ and J. Christine Chiu ${ }^{2}$ \\ Received 24 July 2009; revised 13 April 2010; accepted 21 April 2010; published 7 October 2010. \\ [1] An idealized equilibrium model for the undisturbed partly cloudy boundary layer (BL) \\ is used as a framework to explore the coupling of the energy, water, and carbon cycles \\ over land in midlatitudes and show the sensitivity to the clear-sky shortwave flux, the \\ midtropospheric temperature, moisture, $\mathrm{CO}_{2}$, and subsidence. The changes in the surface \\ fluxes, the $\mathrm{BL}$ equilibrium, and cloud cover are shown for a warmer, doubled $\mathrm{CO}_{2}$ \\ climate. Reduced stomatal conductance in a simple vegetation model amplifies the \\ background $2 \mathrm{~K}$ ocean temperature rise to an (unrealistically large) $6 \mathrm{~K}$ increase in \\ near-surface temperature over land, with a corresponding drop of near-surface relative \\ humidity of about $19 \%$, and a rise of cloud base of about $70 \mathrm{hPa}$. Cloud changes \\ depend strongly on changes of mean subsidence; but evaporative fraction (EF) decreases. \\ $\mathrm{EF}$ is almost uniquely related to mixed layer (ML) depth, independent of background \\ forcing climate. This suggests that it might be possible to infer EF for heterogeneous \\ landscapes from ML depth. The asymmetry of increased evaporation over the oceans \\ and reduced transpiration over land increases in a warmer doubled $\mathrm{CO}_{2}$ climate.
}

Citation: Betts, A. K., and J. C. Chiu (2010), Idealized model for changes in equilibrium temperature, mixed layer depth, and boundary layer cloud over land in a doubled $\mathrm{CO}_{2}$ climate, J. Geophys. Res., 115, D19108, doi:10.1029/2009JD012888.

\section{Introduction}

[2] Atmospheric $\mathrm{CO}_{2}$, a long-lived greenhouse gas, is

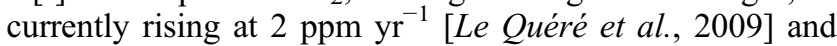
could double this century unless the global economy makes the shift away from burning fossil carbon reserves as our primary energy source. Climate models are being used to project the impact of rising greenhouse gas concentrations on the Earth's climate in the coming century [IPCC, 2007]. However, different models show substantial differences in the planetary energy balance, and many of these differences come from clouds and their coupling to the energy, water, and carbon cycles of the Earth system. This paper will look at one important aspect of this coupling: the sensitivity of boundary layer (BL) equilibrium temperature, mixed layer (ML) depth, and BL cloud over land to a range of external forcing using an idealized BL model coupled to a simple vegetation model [Betts et al., 2004, hereafter B2004]. As $\mathrm{CO}_{2}$ increases, the ratio of evapotranspiration (ET) to the carbon uptake by vegetation over land is expected to decrease because of the coupling of the gas exchange at the leaf level reduces canopy conductance. This process, called "physiological forcing" has been known for some time

\footnotetext{
${ }^{1}$ Atmospheric Research, Pittsford, Vermont, USA. USA.

${ }^{2}$ University of Maryland, Baltimore County, Baltimore, Maryland,

Copyright 2010 by the American Geophysical Union. 0148-0227/10/2009JD012888
}

[Sellers et al., 1996; Betts et al., 1997]. Douville et al. [2000] also discussed the likelihood that leaf area index might increase in a doubled $\mathrm{CO}_{2}$ climate, and this would offset this reduction in canopy conductance. Recently, several studies have explored the detailed impact on land surface feedback. R. A. Betts et al. [2007] showed that climate simulations with doubled $\mathrm{CO}_{2}$ project a $6 \%$ increase in continental runoff due to the reduction in ET. Joshi et al. [2008] and Joshi and Gregory [2008] discuss how reduced ET over the continents reduces near-surface relative humidity $(\mathrm{RH})$ and increases the land-sea temperature contrast. Boucher et al. [2009] found reduced ET gave warming and reduced cloud cover over land in transient climate simulations for the 21 st century with fixed vegetation. Doutriaux-Boucher et al. [2009] explored the same feedbacks in simulations with an instantaneous doubling of $\mathrm{CO}_{2}$ and found similar results, showing that there is a fast climate response on timescales much less than a year.

[3] In global climate models, some aspects of their sensitivity can be explored by turning off feedbacks one-by-one. Nonetheless, sensitivity in land surface and cloud processes varies widely between different climate models [Andrews et al., 2009]. This paper starts from the other extreme. We show the sensitivity of the idealized land model, with vegetationBL-cloud coupling, to specified external "climate" forcing, represented by the shortwave clear-sky flux, midtropospheric temperature and mixing ratio, $\mathrm{CO}_{2}$, and subsidence. For example, the reduction of canopy conductance as midtropospheric $\mathrm{CO}_{2}$ increases (the physiological forcing) 
reduces surface $\mathrm{RH}$ and increases surface temperature, which gives a deeper mixed layer and a higher cloud base. BL cloud cover also changes, so that the surface shortwave and longwave cloud forcings are altered, modifying the surface energy balance of the equilibrium BL system. These sensitivity studies give insight into how clear-sky and cloud radiative feedbacks and a vegetated land surface interact to give different solutions for equilibrium temperature, ML depth, and $\mathrm{BL}$ cloud in response to changes in free tropospheric boundary conditions. Then, the sensitivity of the land surface-BL system to a warmer doubled $\mathrm{CO}_{2}$ climate is shown.

[4] These highly simplified solutions cannot be directly compared with global climate model scenarios for two reasons. The drop of stomatal conductance in the vegetation model in response to warmer temperatures and doubled $\mathrm{CO}_{2}$ is unrealistically large, and the feedbacks from the BL to the atmospheric structure and dynamics are excluded. However, the general modeling framework may be useful in understanding why fully coupled climate models have different sensitivities to, for example, cloud processes. With a better vegetation model, the framework may also be useful in diagnostic studies of the coupling of the carbon and water budgets over land.

[5] The land/sea warming contrast is seen in both equilibrium and transient climate simulations [Joshi et al., 2008]. The smaller thermal inertia of the land surface is important in transient climate simulations. The coupling of the carbon and water cycles at the leaf level through transpiration increases the asymmetry between land and oceans as $\mathrm{CO}_{2}$ rises in the atmosphere and the climate warms. Over the oceans, nearsurface RH and cloud base change little, whereas surface evaporation and the radiative cooling of the troposphere increase with temperature [Betts and Ridgway, 1989]. Over land, the drop of canopy conductance reduces transpiration, and this is one factor contributing to the warming over land being greater than over the ocean in climate model projections for a high $\mathrm{CO}_{2}$ climate [Sellers et al., 1996].

[6] Another broad issue is the relation between $\mathrm{CO}_{2}$ sequestration and changes in the surface energy balance associated with reafforestation [Randerson et al., 2009]. The impact of changes in ET on low cloud cover is one more factor affecting the surface energy balance $[A$. K. Betts et al., 2007] and equilibrium temperature, along with changes in surface albedo [R. A. Betts, 2000]. Currently, there are significant errors in modeling low cloud cover in global models, which in turn can have a major impact on surface temperature errors [Betts et al., 2009].

\section{Equilibrium BL Model}

[7] The model of B2004 couples a simple vegetation model to an idealized equilibrium model for the undisturbed BL, developed earlier in the study by Betts [2000]. In reality, the BL goes through a strong diurnal cycle over land, with an unstable BL during the daytime driven by shortwave heating and a stable BL at night driven by longwave cooling. In a sequence of similar days, such as extended periods of subsidence, a quasi-equilibrium BL state may be reached in which the surface latent heat flux balances the drying from subsidence, and the surface sensible heat flux and subsidence warming are balanced by net radiative cooling. Despite the strong diurnal cycle and a vegetative constraint on surface ET, this equilibrium, integrated over $24 \mathrm{~h}$, is similar to the equilibrium of the BL over the oceans discussed in the study by Betts and Ridgway [1988, 1989]. The equilibrium model of B2004 is a simplified attempt to capture the essence of this balance and find budget solutions for the ML and cloud base mass flux in terms of $24 \mathrm{~h}$ means, while ignoring the complexity of modeling the details of the stable and unstable BLs. This is a gross simplification, but it is useful for giving insight into the BL equilibrium on timescales longer than a day.

[8] The equilibrium assumption is however more than a simplification; it is a strong constraint on the solutions. In essence, we are using equilibrium budget constraints for energy, water, and $\mathrm{CO}_{2}$ to determine ML structure and cloud amount. It is certainly arguable that equilibrium solutions are probably more representative of the tropics than the midlatitudes, where horizontal and vertical advection often plays a major role in determining BL structure. Furthermore, strict BL equilibrium is not possible over land because episodic rain events are essential to maintain soil water, and the BL typically warms up between rain events. However, this simplified model allows us to separate the sensitivities of the ML structure and cloud amount to different physical processes, which is helpful for understanding what changes are robust in a warmer doubled $\mathrm{CO}_{2}$ world. However, the limitations of the equilibrium constraint will be discussed later as they become clear.

\subsection{Vegetation Model}

[9] The simple vegetation model is unchanged from B2004 (see equations (7)-(20) in that paper), and only the details relevant to this paper are summarized here. A canopy photosynthesis model, based on the study by Collatz et al. [1991], has temperature and soil water stress factors and three vegetation parameters: a leaf area index (LAI), a vegetation efficiency $\left(E_{\mathrm{veg}}\right)$, and a respiration temperature dependence $\left(Q_{10}\right)$. From B2004, we will take the nominal midlatitude grassland with a parameter set (LAI, $E_{\mathrm{veg}}, Q_{10}$ ) of $(3,10,2.1)$. The model canopy conductance responds to increasing $\mathrm{CO}_{2}$ (see (3) later), but because these vegetation parameters are fixed, the model is only qualitative for large changes of $\mathrm{CO}_{2}$. We assume all evaporation is stomatally controlled transpiration, so important processes like evaporation of wet soils and wet canopies after precipitation are not included.

[10] Both photosynthesis and respiration are proportional to a soil water stress term ( $F$ stress), which is defined as a quadratic function of fractional soil water content (SWC)

$$
F \text { stress }=-1.4694+13.1 \mathrm{SWC}+17.341 \mathrm{SWC}^{2} .
$$

$F$ stress is zero at a permanent wilting point of 0.137 and unity at 0.361 , so these SWC limits are used to scale our results in terms of a soil water index (SWI), defined to run from 0 to 1

$$
\mathrm{SWI}=(\mathrm{SWC}-0.137) /(0.361-0.137) .
$$

Photosynthesis has an additional quadratic temperature stress term (Ftemp), defined by a simple function of surface 
temperature, $T_{\mathrm{sf}}$ (units, ${ }^{\circ} \mathrm{C}$ ), to be zero at $0^{\circ} \mathrm{C}$ with a maximum near 1 at $26.75^{\circ} \mathrm{C}$.

$$
F \text { temp }=0.0028 T_{\text {sf }}\left(26.75-0.5 T_{\text {sf }}\right) .
$$

Canopy or stomatal conductance, $g_{\mathrm{c}}$, is computed from the photosynthetic flux density, $\mathrm{PH}$ _fd, and the substomatal-toambient $\mathrm{CO}_{2}$ gradient, which is modeled as a function of $\mathrm{CO}_{2 \mathrm{~L}}$ at the leaf [Ball, 1987]

$$
g_{\mathrm{c}}=-1.5 \mathrm{PH} \_\mathrm{fd} /\left(\rho_{\mathrm{mol}} \mathrm{CO}_{2 \mathrm{~L}}\left(1-C_{\mathrm{RH}}\right)\right),
$$

where $C_{\mathrm{RH}}=0.5833+0.1667 \mathrm{RH}_{\mathrm{sf}}$. $\mathrm{RH}_{\mathrm{sf}}$ is the surface $\mathrm{RH}$ at the leaf, and $\rho_{\mathrm{mol}}$ is the molar density conversion between units of velocity (ppm $\mathrm{CO}_{2} \mathrm{~m} \mathrm{~s}^{-1}$ ) and flux density $(\mu \mathrm{mol}$ $\mathrm{CO}_{2} \mathrm{~m}^{-2} \mathrm{~s}^{-1}$ ). Conductance $g_{\mathrm{c}}$ decreases as $F$ stress and Ftemp, defined by (1a) and (2), decrease. $T_{\mathrm{sf}}$ is a computed variable, but a soil water balance equation is not possible for the undisturbed $\mathrm{BL}$ over land with no precipitation, so SWI is a specified external variable that determines the soil water stress and is a key constraint on photosynthesis, respiration, and transpiration.

[11] The vegetation model is coupled to a mixed layer (ML) model, derived from Betts [1973], with balance equations for energy, water, and $\mathrm{CO}_{2}$. Surface transfer equations (see B2004), following Monteith [1981], are used at the base of the mixed layer with a fixed aerodynamic conductance of $0.025 \mathrm{~m} \mathrm{~s}^{-1}$ and a fixed surface pressure set at a nominal $1000 \mathrm{hPa}$. B2004 shows a schematic of the model framework. Equilibrium solutions are found for ML parameters: potential temperature $\left(\theta_{\mathrm{m}}\right)$, mixing ratio $\left(q_{\mathrm{m}}\right)$, and $\mathrm{CO}_{2 \mathrm{~m}}$. At the ML top, we solve for the jumps in all three variables: $\Delta \theta_{\mathrm{b}}, \Delta q_{\mathrm{b}}$, and $\Delta \mathrm{CO}_{2 \mathrm{~b}}$, as well as a cloud base mass flux, given a mean subsidence and other boundary conditions discussed in section 2.4. The cloud base mass flux comes from the constraint that the ML top corresponds to the lifting condensation level (LCL) of ML air $\left(\theta_{\mathrm{m}}, q_{\mathrm{m}}\right)$. We use pressure coordinates, so we define the pressure thickness of the ML, $P_{\mathrm{ML}}=P_{\mathrm{LCL}}$ the pressure height of the LCL above the surface. Our iterative method of solution uses a quadratic relation between $P_{\mathrm{LCL}}$ and the relative humidity $\left(\mathrm{RH}_{\mathrm{LCL}}\right)$ at the base of the ML to couple $q_{\mathrm{m}}$ to $\theta_{\mathrm{m}}$.

[12] Above the ML is a shallow cloud layer, but the model only solves for variables $\theta_{\text {cld }}, q_{\text {cld }}$, and $\mathrm{CO}_{2 \text { cld }}$, at the top of the cloud base jumps. The temperature profile above cloud base is an external variable, specified in terms of a reference potential temperature and a linearized moist adiabat (see section 2.4). The mass exchange at cloud base includes a cloud base mass flux as well as a mean subsidence that is treated as constant from cloud base to the middle troposphere, defined as $650 \mathrm{hPa}$. Boundary conditions are needed in the middle troposphere for potential temperature $\left(\theta_{\mathrm{mid}}\right)$, mixing ratio $\left(q_{\mathrm{mid}}\right)$, and $\mathrm{CO}_{2 \mathrm{mid}}$, and these are also discussed in section 2.4. For the range of parameters, we shall show here that the BL cloud is always nonzero.

\subsection{Surface Radiative Fluxes and Cloud Radiative Forcing}

[13] An essential feature of this simplified uncoupled model is that we use a radiation model to solve offline for the clear-sky surface longwave (LW) and shortwave (SW) radiation fluxes, the clear-sky ML cooling and heating rates, and the LW cloud forcing (LWCF). We then represent them parametrically, primarily in terms of ML depth, which is also cloud base. This is a change from B2004, where reanalysis data were used to estimate the coupling of the radiation fluxes to the cloud field. We calculate the LWCF and SW cloud forcing (SWCF) from the model cloud base mass flux, which we link to an effective SW cloud albedo.

[14] The offline calculations were made with the Santa Barbara discrete ordinates radiative transfer atmospheric radiative transfer (SBDART) model [Ricchiazzi et al., 1998]. We computed shortwave and longwave fluxes at $0.2-4 \mu \mathrm{m}$ and $4-50 \mu \mathrm{m}$ wavelengths, respectively. The incoming solar spectrum follows the database in MODTRAN at a $20 \mathrm{~cm}^{-1}$ spectral resolution. The integrated ozone concentration is $336 \mathrm{~atm} \mathrm{~cm}$, whereas other trace gas amounts are given by default in SBDART. We also assumed a spectrally uniform albedo of 0.15 for the underlying surface. To calculate the surface LW fluxes beneath BL cloud, we placed a $40 \mathrm{hPa}$ thick cloud layer right above the ML. The cloud effective radius is given as $6 \mu \mathrm{m}$, and the liquid water mixing ratio linearly increases to $0.88 \mathrm{~g} \mathrm{~kg}^{-1}$ at the cloud top, corresponding roughly to the adiabatic liquid water content. As a result, the corresponding cloud optical depth is about $\sim 50$ in our calculations. From the surface to just above cloud base, the radiation code uses the computed temperature and moisture profiles. Above cloud base, temperature follows a moist adiabat to $150 \mathrm{hPa}$ and moisture comes from the specification of RH (see section 2.4). We used a $10 \mathrm{hPa}$ vertical resolution up to $650 \mathrm{hPa}$ and a $25 \mathrm{hPa}$ resolution at higher levels. We treat $\mathrm{CO}_{2}$ as a well-mixed gas for the radiation calculations and specify its value.

[15] Clear-sky surface net shortwave, $\mathrm{SW}_{\text {net }}$ (clear), is specified in the BL model, characteristic of a midlatitude daily mean in summer. For the radiation model, we used dayof-year $=235$ for Bondville, IL, at $43.0^{\circ} \mathrm{N},-96.0^{\circ} \mathrm{W}$ and a surface albedo of 0.15 to match closely our standard value of

$$
\mathrm{SW}_{\text {net }}(\text { clear })=250 \mathrm{Wm}^{-2} \text {. }
$$

We will show the sensitivity to $\mathrm{SW}_{\text {net }}($ clear) in section 3.1.

[16] $\mathrm{LW}_{\text {net }}$ (clear) depends strongly on ML depth. We took a base set of parameters for sensitivity studies for the present climate (see section 3) and calculated the surface clear-sky net longwave flux as a function of the ML depth, using profiles from the equilibrium model solutions in which $P_{\mathrm{ML}}$ varies with soil moisture. We then fitted a quadratic representation

$$
\begin{aligned}
\mathrm{LW}_{\text {net }}(\text { clear })= & -67.2-0.03\left(P_{\mathrm{ML}}-90\right) \\
& -0.0044\left(P_{\mathrm{ML}}-90\right)^{2}
\end{aligned}
$$

The surface longwave cooling is reduced with a shallower moister ML. In contrast, the variation of surface $\mathrm{SW}_{\text {net }}$ (clear) with ML depth and tropospheric RH is rather small $\left(\approx \pm 1 \mathrm{Wm}^{-2}\right)$, and we neglected it, except in section 3.1.

[17] Similarly, we also calculated the mean net clear-sky cooling rate $\mathrm{ML}_{\text {cool }}$ (the daily mean longwave cooling, offset by the smaller daytime shortwave absorption in $\mathrm{K}$ $\mathrm{d}^{-1}$ ) from the radiation model and then fitted this quadratic relation

$$
\begin{aligned}
\mathrm{ML}_{\text {cool }}(\text { clear })= & -2.08+0.0079\left(P_{\mathrm{ML}}-90\right)-1.54 \\
& \times 10^{-5}\left(P_{\mathrm{ML}}-90\right)^{2} .
\end{aligned}
$$

As the ML deepens, the mean clear-sky net cooling rate falls. 
[18] The surface SW and LW radiative forcing by BL clouds play an important role in the surface energy budget and the ML equilibrium, and they are introduced in three places as modifications to (4), (5), and (6). We link all three: SWCF, LWCF, and the reduction of the net ML radiative cooling by clouds by defining an effective cloud albedo (ECA) as [Betts, 2009]

$$
\mathrm{ECA}=-\mathrm{SWCF} / \mathrm{SW}_{\text {net }}(\text { clear}) .
$$

We use the cloud base mass flux $\left(\rho_{\mathrm{b}} W_{\mathrm{cld}}\right)$ as a measure of the cloud SW radiative forcing and define a reference cloud mass flux $\left(\rho_{\mathrm{b}} W_{40}\right)$ that corresponds to an ECA $=0.4$, so that

$$
\mathrm{ECA}=0.4\left(\rho_{\mathrm{b}} W_{\text {cld }}\right) /\left(\rho_{\mathrm{b}} W_{40}\right) .
$$

Then the SWCF becomes by definition

$$
\begin{aligned}
\mathrm{SWCF} & =-(\mathrm{ECA}) \mathrm{SW}_{\text {net }}(\text { clear }) \\
& =-0.4 \mathrm{SW}_{\text {net }}(\text { clear })\left(\rho_{\mathrm{b}} W_{\text {cld }}\right) /\left(\rho_{\mathrm{b}} W_{40}\right) .
\end{aligned}
$$

For the LWCF, we calculated surface $\mathrm{LW}_{\text {net }}$ (cloud) with a $40 \mathrm{hPa}$ optically thick cloud just above the ML and again fitted a quadratic relation

$$
\begin{aligned}
\mathrm{LW}_{\text {net }}(\text { cloud })= & -13.8-0.146\left(P_{\mathrm{ML}}-90\right) \\
& -0.0001\left(P_{\mathrm{ML}}-90\right)^{2} .
\end{aligned}
$$

We then defined the LWCF as the difference between (10) and (5), multiplied by the ECA.

$$
\begin{aligned}
\mathrm{LWCF} & =\mathrm{LW}_{\text {net }}(\text { cloud })-\mathrm{LW}_{\text {net }}(\text { clear }) \\
& =\operatorname{ECA}\left(53.4-0.116\left(P_{\mathrm{ML}}-90\right)+0.0043\left(P_{\mathrm{ML}}-90\right)^{2}\right)
\end{aligned}
$$

Because the LW and SW properties of clouds differ, it is an approximation to directly couple the LWCF to the SWCF using the ECA. For this midlatitude summer situation, the LWCF ( $\approx+50$ ECA) is a warming term that partly cancels the cooling from the SWCF $(=-250 \mathrm{ECA}$ for our base case). Finally, underneath an optically thick cloud, the ML cooling is reduced to near-zero, which reduces the net BL cooling in the presence of clouds to

$$
\mathrm{ML}_{\mathrm{cool}}=(1-\mathrm{ECA}) \mathrm{ML}_{\mathrm{cool}}(\text { clear }) .
$$

We set the reference cloud mass flux corresponding to a $40 \%$ ECA to

$$
\rho_{\mathrm{b}} W_{40}=0.01 \mathrm{~kg} \mathrm{~m}^{-2} \mathrm{~s}^{-1}
$$

corresponding to $84.7 \mathrm{hPa} \mathrm{d}$. This is somewhat arbitrary, but it is consistent with the very few estimates over land [e.g., Betts, 1976]. However, the cloud radiative forcing terms are such a tight constraint on the budget system of equations that our results for ECA are only weakly sensitive to this reference cloud mass flux (see section 3.1 later).

\subsection{Surface Energy Balance}

[19] The surface energy balance between sensible heat flux $(H)$, latent heat flux $(\lambda E)$, and net radiation $\left(R_{\text {net }}\right)$ is simply

$$
\begin{aligned}
\lambda E+H=R_{\text {net }}= & \mathrm{SW}_{\text {net }}(\text { clear })+\mathrm{SWCF}+\mathrm{LW}_{\text {net }}(\text { clear }) \\
& +\mathrm{LWCF} .
\end{aligned}
$$

At equilibrium, there is no storage term, and we neglect the small photosynthetic term. Evaporative fraction is defined as

$$
\mathrm{EF}=\lambda E /(\lambda E+H) .
$$

\subsection{Boundary Conditions Above Cloud Base}

[20] Potential temperature from just above cloud base to the middle troposphere, defined as $650 \mathrm{hPa}$, is related to an "oceanic" reference profile, defined as

$$
\theta(p)=\theta_{00}+\Gamma_{\mathrm{w}}(950-p),
$$

where $\Gamma_{\mathrm{w}}=-\mathrm{d} \theta_{\mathrm{w}} / \mathrm{d} p$ is a linearized slope of the moist adiabat through $\left(\theta_{00}, 950\right)$. For the present and doubled $\mathrm{CO}_{2}$ climates, we set a reference potential temperature $\theta_{00}=(297$, $299 \mathrm{~K})$, respectively. In conceptual terms, we are specifying the temperature structure above cloud base in our continental BL model in terms of the moist adiabat though a typical oceanic cloud base of $950 \mathrm{hPa}$, with a $2 \mathrm{~K}$ warmer potential temperature at the sea surface (and at cloud base) in a doubled $\mathrm{CO}_{2}$ world. This is broadly consistent with the summer midlatitude ocean warming in the A1B scenario at the end of the 21 st century [IPCC, 2007]. This couples the global-scale warming to our BL model through the upper boundary condition. The results are not sensitive to choosing a more unstable lapse rate such as the moist virtual adiabat. The key role played by (16) in the solution is that it determines $\theta_{\text {cld }}$ just above cloud base from $P_{\mathrm{ML}}$, as well as midtropospheric $\theta_{\text {mid }}$.

[21] $\mathrm{CO}_{2 \mathrm{mid}}$ is specified as $380 \mathrm{ppm}$ for present day climate and $760 \mathrm{ppm}$ for a doubled $\mathrm{CO}_{2}$ climate, and from this, the model solution gives $\mathrm{CO}_{2}$ at the leaf, for the $\mathrm{ML}$ and above cloud base. We determine $q_{\text {mid }}$ by specifying $\mathrm{RH}_{\text {mid }}$ at $650 \mathrm{hPa}$. This directly couples $q_{\text {mid }}$ to $\theta_{\text {mid }}$. In section 3.3 , we show the sensitivity to varying $\mathrm{RH}_{\text {mid }}$ in the range $20 \%$ $50 \%$. In B2004, the mixing ratio $q_{\mathrm{cld}}$ above cloud base was found by specifying RH just above cloud base; and the equilibrium determined the subsidence as well as the cloud base mass flux. Here we specify $\mathrm{RH}_{\text {mid }}$ and the mean subsidence from cloud base to the midtroposphere, and $q_{\text {cld }}$ becomes part of the equilibrium solution, along with $q_{\mathrm{m}}$.

[22] For the calculations of the clear-sky radiation fluxes, we specify a temperature profile from the moist adiabat (16) from just above cloud base to $150 \mathrm{hPa}$. For moisture, we linearly interpolate between $q_{\text {cld }}$ and $q_{\text {mid }}$ from just above cloud base to $650 \mathrm{hPa}$ and then specify $\mathrm{RH}=\mathrm{RH}_{\text {mid }}$ from 650 to $150 \mathrm{hPa}$. Above $150 \mathrm{hPa}$, we simply specify typical midlatitude profiles and keep them fixed.

[23] Not surprisingly, midtropospheric subsidence has an important impact on the solutions, and it is particularly important for the cloud mass flux. Our specified baseline subsidence, $\rho_{\mathrm{b}} W_{\text {sub }}$ at cloud base (and constant up to the middle troposphere, with uniform divergence in the ML) is a mass flux of $0.005 \mathrm{~kg} \mathrm{~m}^{-2} \mathrm{~s}^{-1}$ for the present climate, corresponding to $42.3 \mathrm{hPa} \mathrm{d}^{-1}$. This choice is somewhat arbitrary, so we will show the sensitivity to subsidence over a wide range in section 3.2. In addition, we have limited understanding how the subsiding branches of the atmospheric circulations will change in a warmer, high $\mathrm{CO}_{2}$ climate. Several studies have suggested that the subsiding mass flux will decrease in a warmer climate [Betts, 1998; Held and Soden, 2006] because precipitation, which balances radiative cooling of the atmosphere, increases less 

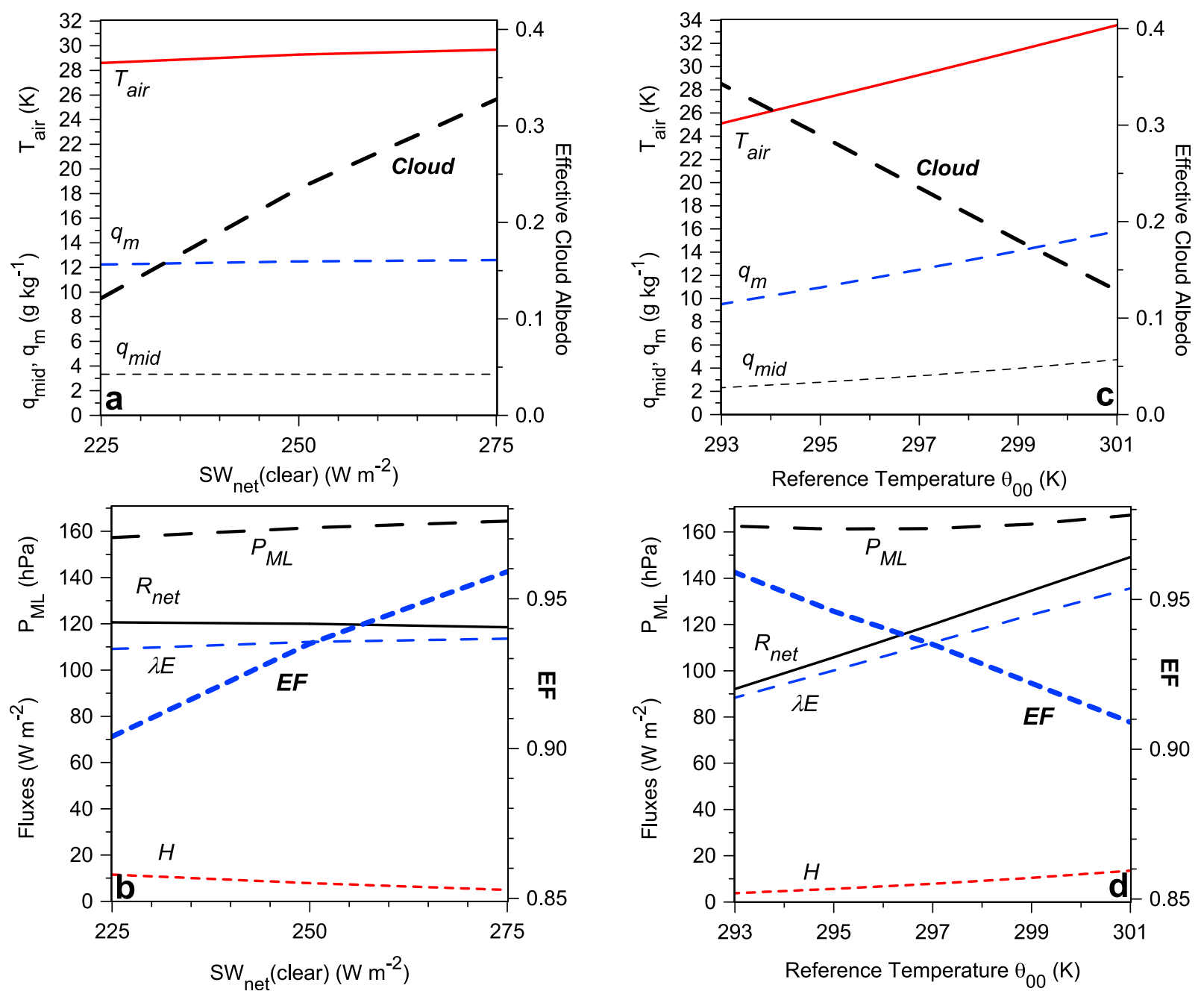

Figure 1. Sensitivity of (a) $T_{\text {air }}, q_{\mathrm{m}}, q_{\text {mid }}$, and effective cloud albedo, (b) surface fluxes, EF and ML depth to $\mathrm{SW}_{\text {net }}$ (clear). (c and d) Same as Figures $1 \mathrm{a}$ and $1 \mathrm{~b}$ for sensitivity to reference temperature, $\theta_{00}$.

rapidly with temperature than saturation mixing ratio. So in section 4 for a doubled $\mathrm{CO}_{2}$ climate, we will show solutions for this same baseline and a $10 \%$ reduction of the mean subsidence to $0.0045 \mathrm{~kg} \mathrm{~m}^{-2} \mathrm{~s}^{-1}$.

\section{Sensitivity to Boundary Conditions}

[24] Sensitivity tests give valuable insight into the structure of the equilibrium BL solutions and their dependence on specified external boundary conditions. They will be used also in section 3.1 as a framework to illustrate the BL budget constraints. We choose a single soil water value, $\mathrm{SWC}=0.2$ $(\mathrm{SWI}=0.281)$. Our baseline set of parameters, which will each be varied separately, are $\mathrm{SW}_{\text {net }}$ (clear) $=250 \mathrm{Wm}^{-2} ; \theta_{00}=$ $297 \mathrm{~K}, \mathrm{RH}_{\text {mid }}=40 \%$, and $\mathrm{CO}_{2 \mathrm{mid}}=380 \mathrm{ppm}$ representative of a midlatitude present-day summer climate; and a subsidence above cloud base of $\rho_{\mathrm{b}} W_{\text {sub }}=0.005 \mathrm{~kg} \mathrm{~m}^{-2} \mathrm{~s}^{-1}$.

\subsection{Sensitivity to Clear-Sky Surface Net Shortwave and Reference Temperature}

[25] Figures $1 \mathrm{a}$ and $1 \mathrm{~b}$ show the sensitivity to $\mathrm{SW}_{\text {net }}$ (clear). We included a small correction for the change in SW absorption in $\mathrm{ML}_{\text {cool }}$ (clear) in (6). The striking feature of Figure 1a is that with larger $\mathrm{SW}_{\text {net }}$ (clear), the effective cloud albedo (related to the cloud base mass flux by (8)), increases sharply, so that the rise of near-surface air temperature $\left(T_{\text {air }}\right)$ is small, and $R_{\text {net }}$, shown in Figure $1 \mathrm{~b}$, barely changes. $T_{\text {air }}$ is computed at the base of the ML from ML $\theta_{\mathrm{m}}$ and the surface pressure of $1000 \mathrm{hPa}$. There is a small readjustment of the sensible heat flux $(H)$ and latent heat flux $(\lambda E)$ so that EF increases, while the ML depth $\left(P_{\mathrm{ML}}\right)$ increases slightly.

[26] Figures $1 \mathrm{c}$ and $1 \mathrm{~d}$ show the corresponding sensitivity to the reference potential temperature $\theta_{00}$, which determines the temperature structure above the ML though (16), for fixed $\mathrm{SW}_{\text {net }}$ (clear) $=250 \mathrm{Wm}^{-2}$. We included a small correction for the change in $\mathrm{LW}$ fluxes with temperature for $\mathrm{LW}_{\text {net }}$ (clear) in (5) and for $\mathrm{ML}_{\text {cool }}$ (clear) in (6). As $\theta_{00}$ increases, Figure 1c shows that effective cloud albedo falls sharply and the ML gets warmer and moister. Air temperature, $q_{\mathrm{m}}$, and midtropospheric $q_{\mathrm{mid}}$ all increase with the reference temperature $\theta_{00}$. Figure $1 \mathrm{~d}$ shows that $R_{\text {net }}, H$, and $\lambda E$ all increase (as cloud decreases) and the ML depth barely changes. To summarize the Figure 1 sensitivities, cloud base, corresponding to $P_{\mathrm{ML}}$, barely changes, but there is a substantial change in effective cloud albedo of order $20 \%-22 \%$; whereas $T_{\text {air }}$ and $q_{\mathrm{m}}$ are coupled to the reference moist adiabat above the ML, not to the clear-sky $\mathrm{SW}_{\text {net }}$. 

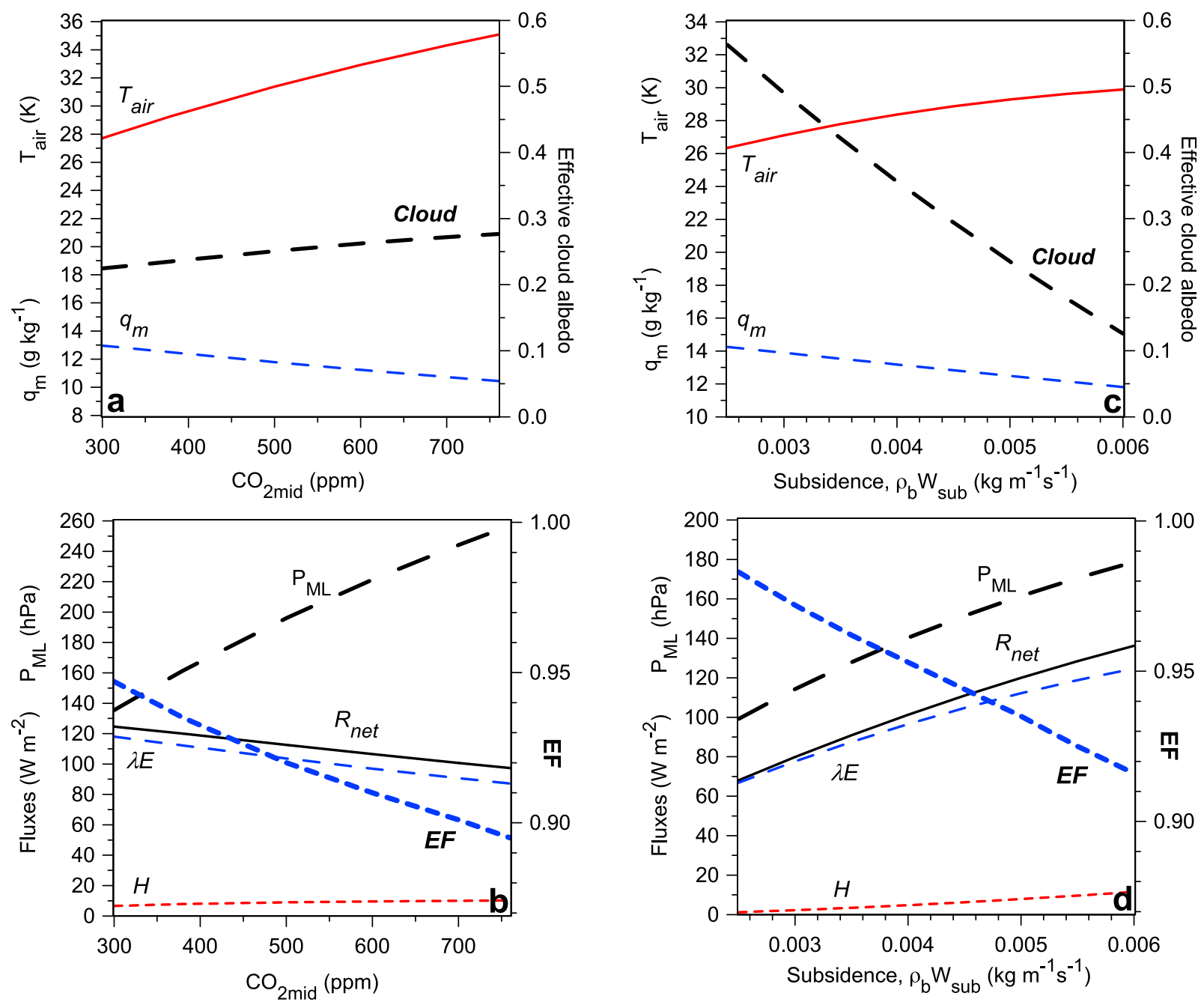

Figure 2. As Figure 1 for sensitivity to $\mathrm{CO}_{2}$ and subsidence.

[27] The equilibrium BL budgets help with understanding the Figures. The BL water budget is the steady state balance between $\lambda E$, the transport of water through cloud base and the subsidence of dry air

$$
\lambda E=L \rho_{\mathrm{b}} W_{\text {sub }}\left(q_{\mathrm{m}}-q_{\mathrm{mid}}\right)=L\left(\rho_{\mathrm{b}} W_{\mathrm{sub}}+\rho_{\mathrm{b}} W_{\mathrm{cld}}\right)\left(q_{\mathrm{m}}-q_{\mathrm{cld}}\right) .
$$

Consider the first balance for fixed subsidence. In Figure 1a, $q_{\text {mid }}$ is fixed, so this balance links the very small changes in $q_{\mathrm{m}}$ and $\lambda E$ changes in Figure $1 \mathrm{~b}$. In Figures $1 \mathrm{c}, q_{\mathrm{mid}}$, which is $40 \%$ of saturation increases with $\theta_{\text {mid }}$ at $650 \mathrm{hPa}$; but as $\theta_{00}$ increases, $q_{\mathrm{m}}$ always increases faster than $q_{\text {mid }}$. Consequently, $\lambda E$ must also increase, which requires a higher $R_{\text {net }}$ (given a thermal constraint (18) on $H$ ) and thus a lower effective cloud albedo. Joshi et al. [2008] point out the importance of the nonlinearity of the Clausius-Clapeyron equation in determining BL structure and land-sea temperature contrast in climate change simulations.

[28] The ML thermal budget is

$$
\begin{aligned}
H= & -\left(C_{\mathrm{p}} / g\right) \mathrm{ML}_{\text {cool }} P_{\mathrm{ML}}+C_{\mathrm{p}}\left(\rho_{\mathrm{b}} W_{\text {sub }}+\rho_{\mathrm{b}} W_{\text {cld }}\right) \\
& \cdot\left(\theta_{\mathrm{m}}-\theta_{\text {cld }}\right) .
\end{aligned}
$$

Here the last term is the negative flux of heat at cloud base. This is a small fraction of the surface heat flux: It is modeled using the traditional ML closure in which the ratio of the cloud base virtual heat flux to the surface virtual heat flux is -0.2 (see B2004 for details). As a result, $H$ is tightly constrained by the product $\mathrm{ML}_{\text {cool }} P_{\mathrm{ML}}$. In Figure $1 \mathrm{~b}, H$ decreases despite the small increase of $P_{\mathrm{ML}}$ because the increase of cloud reduces $\mathrm{ML}_{\mathrm{cool}}$ in (12). In Figure 1d, the decrease of cloud increases $\mathrm{ML}_{\mathrm{cool}}$ and $H$.

[29] Now consider the fluxes and jumps at cloud base. From (16) for a land surface pressure of $1000 \mathrm{hPa}$,

$$
\theta_{\mathrm{cld}}=\theta_{00}+\Gamma_{\mathrm{w}}\left(P_{\mathrm{ML}}-50\right) \text {. }
$$

Given $P_{\mathrm{ML}}$, this links $\theta_{\text {cld }}$ tightly to $\theta_{00}$ and because the cloud base jump $\Delta \theta_{\mathrm{b}}=\left(\theta_{\text {cld }}-\theta_{\mathrm{m}}\right)$ is constrained by the cloud base virtual heat flux closure, this couples $\theta_{\mathrm{m}}$ to $\theta_{00}$ and $P_{\mathrm{ML}}$. In (17) the last term, the cloud base water flux, balances $\lambda E$, but this does not determine $q_{\text {cld }}$ and cloud mass flux $\rho_{\mathrm{b}} W_{\text {cld }}$ separately. In fact, rearranging (17) simply gives the conceptually useful diagnostic relation

$$
\rho_{\mathrm{b}} W_{\mathrm{cld}}\left(q_{\mathrm{m}}-q_{\mathrm{cld}}\right)=\rho_{\mathrm{b}} W_{\mathrm{sub}}\left(q_{\mathrm{cld}}-q_{\mathrm{mid}}\right),
$$



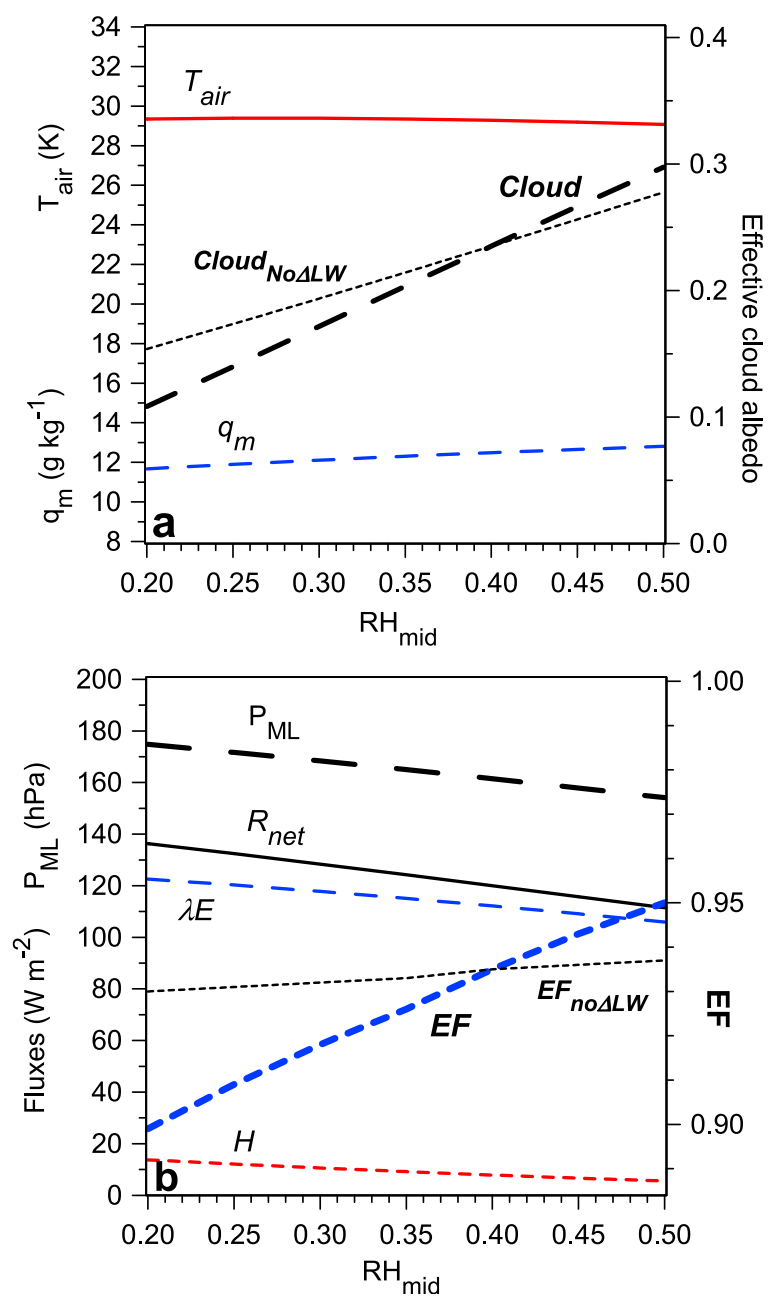

Figure 3. As Figures $2 \mathrm{a}$ and $2 \mathrm{~b}$ for sensitivity to midtropospheric RH (see text for no $\Delta \mathrm{LW}$ plots).

which shows $q_{\mathrm{cld}} \rightarrow q_{\text {mid }}$ as $\rho_{\mathrm{b}} W_{\text {cld }} \rightarrow 0$. The constraints at cloud base are both flux constraints, and cloud cover is tightly coupled to the ML equilibrium and $R_{\text {net }}$ through the cloud radiative forcing terms, in (9), (11), and (12). The magnitude of the cloud mass flux is largely determined by setting the reference cloud mass flux, $\rho_{\mathrm{b}} W_{40}=0.01 \mathrm{~kg} \mathrm{~m}^{-2}$ $\mathrm{s}^{-1}$ to correspond to a $40 \%$ shortwave ECA. For our base case, if we increase $\rho_{\mathrm{b}} W_{40}$ by $50 \%$ to $0.015 \mathrm{~kg} \mathrm{~m}^{-2} \mathrm{~s}^{-1}$, the cloud mass flux increases by $45 \%$; but the ECA only decreases from $23.5 \%$ to $22.5 \%$ and the changes in $P_{\mathrm{ML}}, T_{\text {air }}$, $q_{\mathrm{m}}$, and $\mathrm{CO}_{2 \mathrm{~m}}$ are also small (not shown).

[30] Although the ECA is strongly constrained by the water and energy budgets, this uncertainty in cloud mass flux does affect $q_{\text {cld }}$ (through (20)) and similarly $\mathrm{CO}_{2 \text { cld }}$. Analogous to (17), the net ecosystem exchange (NEE) in $\mu \mathrm{mol} \mathrm{CO} \mathrm{Cm}^{-2} \mathrm{~s}^{-1}$ satisfies the two balances

$$
\begin{aligned}
\mathrm{NEE} & =34.52 \rho_{\mathrm{b}} W_{\text {sub }}\left(\mathrm{CO}_{2 \mathrm{~m}}-\mathrm{CO}_{2 \mathrm{mid}}\right) \\
& =34.52\left(\rho_{\mathrm{b}} W_{\text {sub }}+\rho_{\mathrm{b}} W_{\text {cld }}\right)\left(\mathrm{CO}_{2 \mathrm{~m}}-\mathrm{CO}_{2 \mathrm{cld}}\right),
\end{aligned}
$$

where $34.52=287 / 8.314$ is the ratio of the gas constant in $\mathrm{J}$ $\mathrm{kg}^{-1} \mathrm{~K}^{-1}$ to $\mathrm{J}$ mol K${ }^{-1}$. If we increase $\rho_{\mathrm{b}} W_{40}$ from 0.01 to
$0.015 \mathrm{~kg} \mathrm{~m}^{-2} \mathrm{~s}^{-1}$, the increase of cloud mass flux increases $q_{\text {cld }}$ by $+0.9 \mathrm{~g} \mathrm{~kg}^{-1}$ (from (20)), whereas $\mathrm{CO}_{2 \text { cld }}$ falls by $-1.0 \mathrm{ppm}$ (from (21)). Careful measurements of the coupling of the $q$ and $\mathrm{CO}_{2}$ profiles though the convective $\mathrm{BL}$, together with measurements of SWFC and subsidence from data assimilation might be used to constrain cloud mass fluxes and improve our estimate of reference mass flux $\rho_{\mathrm{b}} W_{40}$.

[31] One important result from Figure 1 is that, although cloud amount is very sensitive, ML depth is very insensitive to clear-sky forcing, and reference temperature. The feedbacks to the vegetation model are also small, and canopy conductance changes little (not shown).

[32] Can these solutions tell us anything about the real world? On timescales of a few days, the model suggests that, with no change of subsidence, cloud cover will tend to be higher with colder midtropospheric temperatures, whereas aerosols that reduce the clear-sky shortwave flux may reduce cloud cover. Over the seasonal cycle, both $\mathrm{SW}_{\text {net }}$ (clear) and $\theta_{00}$ will change together (although $\theta_{00}$ will lag), and their impacts on cloud cover may partly cancel. On the timescale of climate change, the warming of $\theta_{00}$ of $+2 \mathrm{~K}$ from the longwave greenhouse effect will reduce cloud cover, but it will have little effect on ML depth.

\subsection{Sensitivity to $\mathrm{CO}_{2}$ and Subsidence}

[33] Figures $2 a$ and $2 b$ show the sensitivity of the thermodynamic structure and fluxes to $\mathrm{CO}_{2 \text { mid }}$ with fixed baseline subsidence, soil water, and reference temperature. Again, we computed and included, as modifications to (5) and (6), the small sensitivities of the LW fluxes to changing $\mathrm{CO}_{2}$. The $\mathrm{BL}$ sensitivity to $\mathrm{CO}_{2}$ comes directly from the decrease of canopy conductance in the vegetation model with increasing $\mathrm{CO}_{2}$. The equilibrium response is simple: the ML warms, dries, and gets much deeper, and EF falls. Note that the scales on Figure $2 b$ have a wider range than Figure $1 \mathrm{~b}$. Effective cloud albedo increases slightly and $R_{\text {net }}$ decreases slightly. This equilibrium BL response is the surface physiological forcing with this vegetation model to changes in $\mathrm{CO}_{2}$. Although our model response is probably too large, several key features may become observable in coming decades as global $\mathrm{CO}_{2}$ rises. For a doubling of $\mathrm{CO}_{2}$, the drop of $\mathrm{RH}_{\mathrm{LCL}}$ at the base of the ML is $19 \%$ for this undisturbed land BL (with fixed SWI, $\theta_{00}$, and this vegetation model with fixed internal parameters) with a rise in cloud base of $95 \mathrm{hPa}$. The increase of effective cloud albedo for the $\mathrm{CO}_{2}$ change from 380 to $760 \mathrm{ppm}$ at $\theta_{00}=297 \mathrm{~K}$ is about $4 \%$; but a $2 \mathrm{~K}$ rise of reference temperature gives a larger $5 \%$ drop of cloud (Figure 1c).

[34] Figures $2 \mathrm{c}$ and $2 \mathrm{~d}$ shows the sensitivity to varying the subsidence $\rho_{\mathrm{b}} W_{\text {sub }}$ above the ML from 0.0025 to $0.006 \mathrm{~kg}$ $\mathrm{m}^{-1} \mathrm{~s}^{-1}$, corresponding roughly to the range $21-51 \mathrm{hPa} \mathrm{d}^{-1}$. Here changing subsidence produces significant changes in ML structure, and we included, as modifications to (5) and (6), the corresponding sensitivities of the LW fluxes. Figure $2 \mathrm{c}$ shows that as subsidence increases, air temperature increases, ML $q_{\mathrm{m}}$ drops, and effective cloud albedo drops steeply by $44 \%$. This increases $R_{\text {net }}, H$, and $\lambda E$, although $\mathrm{EF}$ falls. With the warming and drying, the ML deepens.

[35] In the water vapor balance (17), the fall of $q_{\mathrm{m}}$ offsets the increase of $\rho_{\mathrm{b}} W_{\mathrm{sub}}$. This reduces the rise of $\lambda E$, which in turn is coupled to the increase of $R_{\text {net }}$ and reduced cloud. 
Table 1. External Boundary Conditions for BL Model for Climate Change Solutions

\begin{tabular}{lcccccc}
\hline Label & $\mathrm{CO}_{2 \text { mid }}(\mathrm{ppm})$ & $\theta_{00}(\mathrm{~K})$ & $\Gamma_{\mathrm{w}}\left(\mathrm{K} \mathrm{hPa}^{-1}\right)$ & $\theta_{\text {mid }}(\mathrm{K})$ & $\mathrm{RH}_{\text {mid }}(\%)$ & $\rho_{\mathrm{b}} W_{\text {sub }}\left(\mathrm{kg} \mathrm{m}^{-2} \mathrm{~s}^{-1}\right)$ \\
\hline 380 & 380 & 297 & 0.0582 & 313.9 & equation (22) & 0.005 \\
760 & 760 & 299 & 0.0612 & 316.7 & equation (22) & 0.005 \\
$760 \mathrm{~S}$ & 760 & 299 & 0.0612 & 316.7 & equation (22) & 0.0045 \\
\hline
\end{tabular}

\subsection{Sensitivity to Midtropospheric RH}

[36] Figure 3 shows the sensitivity to $\mathrm{RH}_{\text {mid }}$, with fixed baseline subsidence, soil water, reference temperature, and $\mathrm{CO}_{2}$. Changing $\mathrm{RH}_{\text {mid }}$ changes the $\mathrm{ML}$ structure and the water vapor in the free troposphere, so we included, as modifications to (5) and (6), the corresponding sensitivities of the surface $\mathrm{LW}_{\text {net }}$ (clear) and $\mathrm{ML}_{\text {cool }}$ (clear). We ignored a very small change in $\mathrm{SW}_{\text {net }}$ (clear). As might be expected, the entrainment of moister air slightly moistens and cools the ML, which lowers cloud base. Both EF and cloud cover increase with $\mathrm{RH}_{\text {mid }}$. The impact of $\mathrm{RH}_{\text {mid }}$ on the ML comes directly from $\mathrm{BL}$ entrainment and indirectly from the change in the ML LW fluxes from the increase in the water vapor "greenhouse" as the middle and upper troposphere, where $\mathrm{RH}$ increases because it was set equal to $\mathrm{RH}_{\text {mid }}$. To show the significance of this LW radiative change, we show (dotted) $\mathrm{EF}_{\text {no } \Delta \mathrm{LW}}$ and cloud $\mathrm{no}_{\mathrm{n}} \mathrm{LW}$, with the changes in $\mathrm{ML}$ radiative fluxes removed. The LW radiative coupling is responsible for most of the change of EF but for only about $33 \%$ of the total cloud change.

[37] This clear-sky LW coupling is a nonlocal connection between tropospheric moisture and the ML, and it raises questions about how to specify tropospheric moisture in our climate change solutions, where we are going to vary soil moisture over a wide range. We have no soil water budget and no tropospheric moisture budget but drier soils give deep MLs. The choice we made was to directly couple $\mathrm{RH}_{\text {mid }}$ to $P_{\mathrm{ML}}$ with the simple closure

$$
\mathrm{RH}_{\text {mid }}=0.45-0.001\left(P_{\mathrm{ML}}-90\right) .
$$

Our typical climate change solutions have $90<P_{\mathrm{ML}}<$ $290 \mathrm{hPa}$ as soil water decreases (see next section), so $\mathrm{RH}_{\text {mid }}$ drops from about $45 \%-25 \%$ as the ML gets deeper and drier over this range.

\section{Climate Change Solutions}

[38] Equilibrium solutions will be presented (using our simple grassland vegetation model) for the present-day summer climate in midlatitudes, with an atmospheric $\mathrm{CO}_{2}$ concentration of $380 \mathrm{ppm}$, and a late $21 \mathrm{st}$ century warmer climate with a doubled atmospheric $\mathrm{CO}_{2}$ of $760 \mathrm{ppm}$. We

Table 2. Coefficients for Equations (5'), (6'), and (10')

\begin{tabular}{lcccc}
\hline Case & Baseline (5) (6) (10) & 380 & 760 & $760 \mathrm{~S}$ \\
\hline$A$ & -79.7 & -77.2 & -70.7 & -70.7 \\
$B$ & -0.024 & -0.08 & -0.074 & -0.077 \\
$C$ & -0.0056 & -0.00041 & -0.0004 & -0.0004 \\
$D$ & -1.76 & -1.66 & -1.76 & -1.70 \\
$E$ & 0.007 & 0.0046 & 0.0046 & 0.0042 \\
$F$ & $-1.4 \mathrm{E}-5$ & $-6.5 \mathrm{E}-06$ & $-4.6 \mathrm{E}-06$ & $-4.2 \mathrm{E}-06$ \\
$\mathrm{AC}$ & -16.1 & -16.1 & -15.9 & -15.9 \\
$\mathrm{BC}$ & -0.167 & -0.166 & -0.156 & -0.154 \\
$\mathrm{CC}$ & -0.00012 & -0.00013 & -0.00013 & -0.00014 \\
\hline
\end{tabular}

fix $\mathrm{SW}_{\text {net }}($ clear $)=250 \mathrm{~W} \mathrm{~m}^{-2}$. The increase in tropospheric temperature above cloud base in the warmer climate comes from (16) as the reference potential temperature $\theta_{00}$ increases from 297 to $299 \mathrm{~K}$. For the warmer, doubled $\mathrm{CO}_{2}$ climate, we also show solutions for reduced subsidence in the lower middle troposphere. Table 1 summarizes these three cases, showing their boundary conditions and giving the labels used in the figures.

[39] First in section 4.1 we will show our fits to the radiation model for these three base cases. Then in section 4.2 we show figures that summarize the fluxes, the ML state, the canopy conductance, and carbon balance as a function of soil water index. In section 4.3 we show the simplification that results when the surface fluxes and ML thermodynamic state are expressed as a function of ML depth.

\subsection{Calculated Surface $L_{\text {net }}$ and ML Cooling Rates}

[40] We generalized equations (5), (6), and (10) to the form

$$
\begin{gathered}
\mathrm{LW}_{\text {net }}(\text { clear })=A+B\left(P_{\mathrm{ML}}-90\right)+C\left(P_{\mathrm{ML}}-90\right)^{2} \\
\mathrm{ML}_{\text {cool }}(\text { clear })=D+E\left(P_{\mathrm{ML}}-90\right)+F\left(P_{\mathrm{ML}}-90\right)^{2} \\
\mathrm{LW}_{\text {net }}(\text { cloud })=\mathrm{AC}+\mathrm{BC}\left(P_{\mathrm{ML}}-90\right)+\mathrm{CC}\left(P_{\mathrm{ML}}-90\right)^{2}
\end{gathered}
$$

We then calculated the coefficients by varying SWI for the three cases in Table 1. Because we are uncoupling what is a radiatively coupled problem in which the ML structure depends on the radiation terms, this required an iteration.

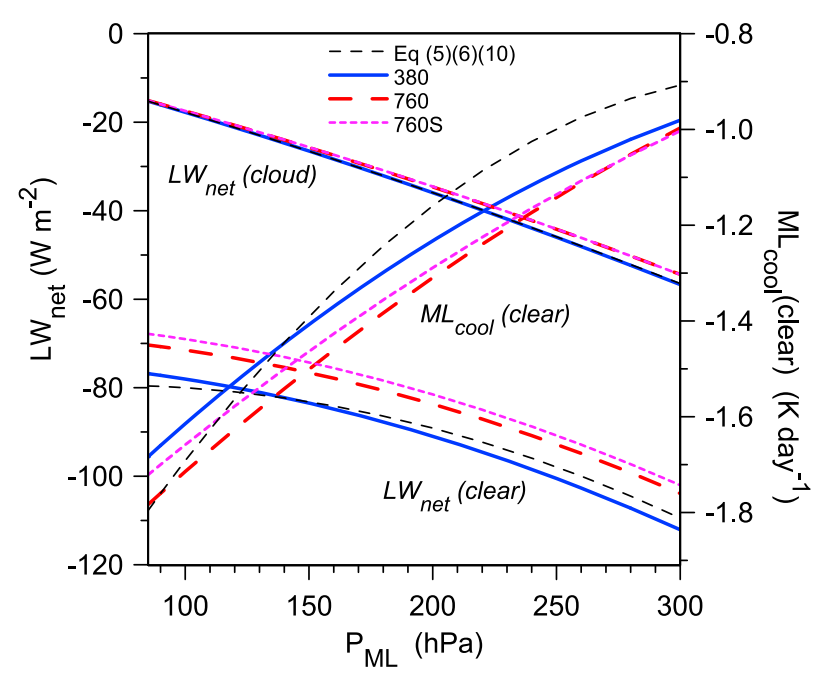

Figure 4. Variation with ML depth of clear and cloudy surface $\mathrm{LW}_{\text {net }}$ and mean clear-sky ML net cooling rate, $\mathrm{ML}_{\text {cool }}$ (clear). 

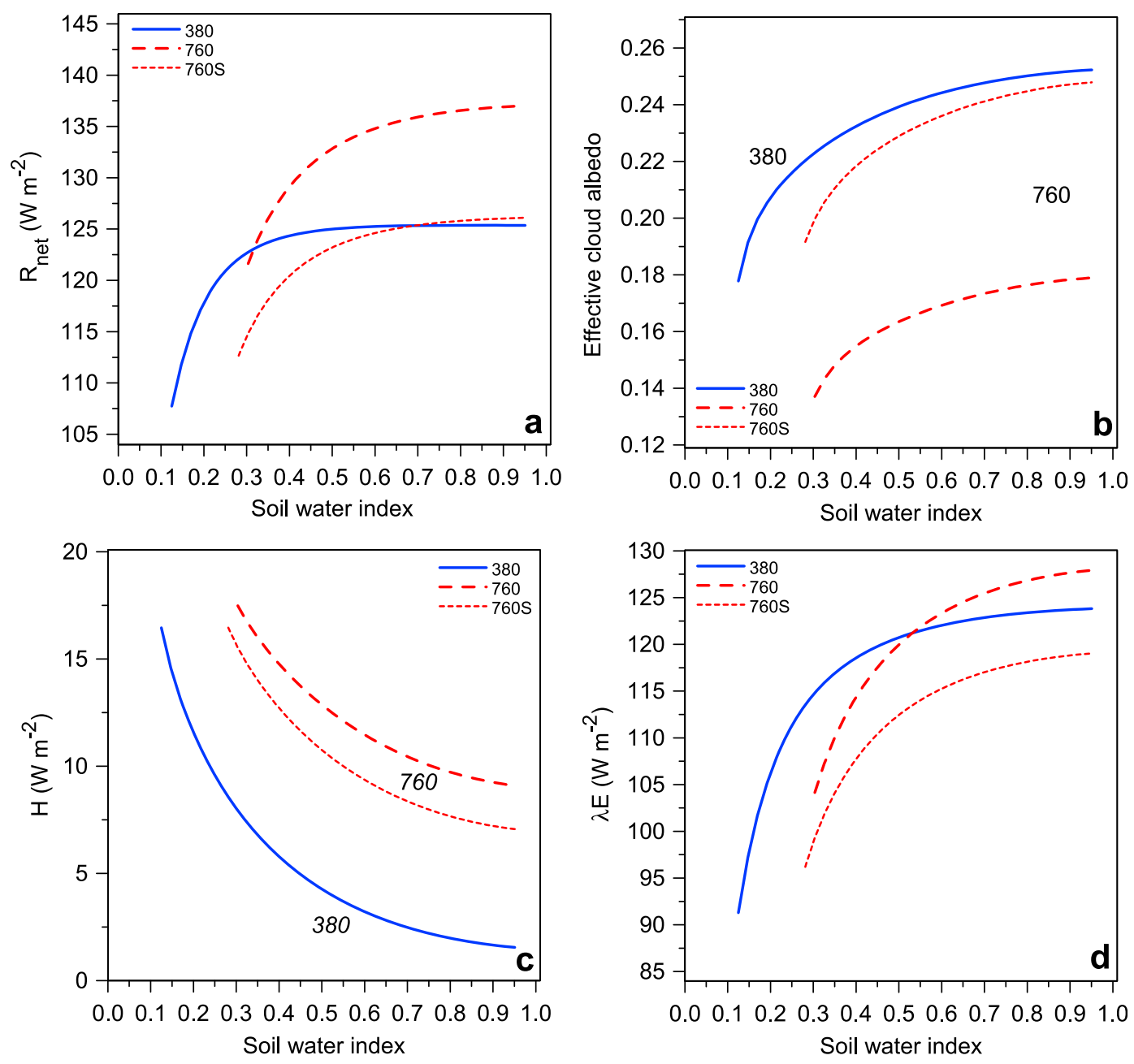

Figure 5. Variation with soil water index of (a) net radiation $R_{\text {net }}$, (b) effective cloud albedo, (c) sensible heat flux $H$, and (d) latent heat flux $\lambda E$.

Table 2 shows the coefficients for these three cases, as well as the baselines equations (5), (6), and (10), which were used for the sensitivity tests in the last section.

[41] Figure 4 shows the surface clear and cloudy $\mathrm{LW}_{\text {net }}$ and $\mathrm{ML}_{\text {cool }}$ (clear), the mean net clear-sky ML cooling rate (clear-sky LW cooling minus SW heating) for all four cases. $\mathrm{LW}_{\text {net }}$ (cloud) falls as the ML deepens, and the slope decreases a little at warmer temperatures. For $\mathrm{LW}_{\text {net }}$ (clear), the fall with $P_{\mathrm{ML}}$ is more nonlinear. The fall of tropospheric humidity with $P_{\mathrm{ML}}$, given by (22), is responsible for the three climate change cases having a steeper slope with $P_{\mathrm{ML}}$ than the baseline (5). Between the cases 380 and 760, the outgoing $\mathrm{LW}_{\text {net }}$ (clear) is reduced by about $7 \mathrm{Wm}^{-2}$, of which about $5 \mathrm{Wm}^{-2}$ comes from the increase in $\theta_{00}$ of $2 \mathrm{~K}$ and about $2 \mathrm{Wm}^{-2}$ from the doubling of $\mathrm{CO}_{2}$. Case 760S, with reduced subsidence has slightly reduced outgoing $\mathrm{LW}_{\text {net }}$ (clear).

[42] The net ML cooling, changes from about -1.8 to $-1 \mathrm{~K}$ $\mathrm{d}^{-1}$ with a deeper ML. The baseline case (6) has the steepest slope; adding the gradient of $\mathrm{RH}_{\text {mid }}$ reduces the slope, and the lower subsidence reduces the slope still further. The change of $\mathrm{ML}_{\mathrm{cool}}$ of about $-0.1 \mathrm{~K} \mathrm{~d}^{-1}$ between the cases 380 and 760 comes from the cancellation of $-0.17 \mathrm{~K} \mathrm{~d}^{-1}$, from the increase from $\theta_{00}$, and $+0.07 \mathrm{~K} \mathrm{~d}^{-1}$ from the greenhouse impact of doubled $\mathrm{CO}_{2}$.

[43] These values for $\mathrm{ML}_{\text {cool }}$ (clear), particularly for large $P_{\mathrm{ML}}$ are significantly smaller than values for moist BLs in the tropics [Betts and Ridgway, 1988, 1989]. Cloud cover can only reduce this net cooling further through (12). This has important consequences because equation (18) keeps values for $H$ relatively low even for deep MLs. This raises the question, which we will discuss in section 5, whether the equilibrium assumption is really applicable for these midlatitude BLs.

\subsection{Dependence on Soil Water Index}

[44] Figure 5 summarizes the surface energy and cloud base mass fluxes as a function of soil water index (SWI), which has a large impact on soil water stress (1a), canopy conductance (3), and the surface energy partition (14). The fall of $R_{\text {net }}$ for low SWI, shown in Figure 5a, is dominated by the increase of outgoing $\mathrm{LW}_{\text {net }}$ (clear) as the ML deepens (Figure 4). The reduction in the cloud forcing at low SWI, as effective cloud albedo falls, is somewhat smaller, only about $10 \mathrm{Wm}^{-2}$. 


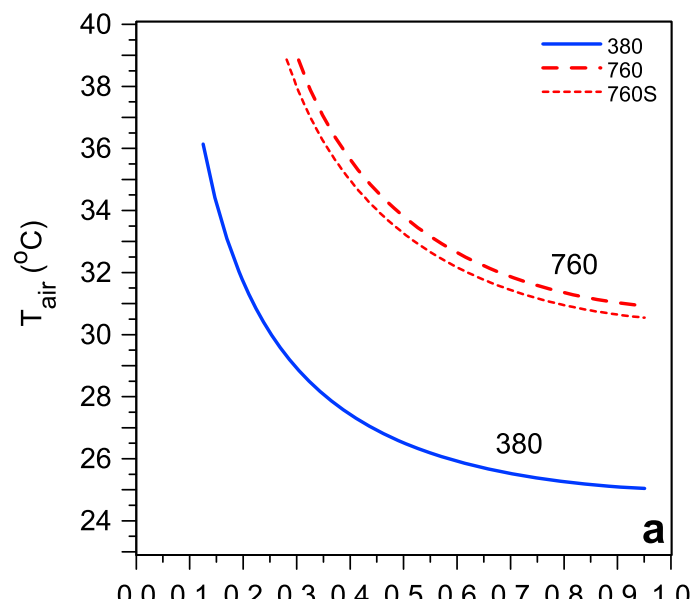

Soil water index

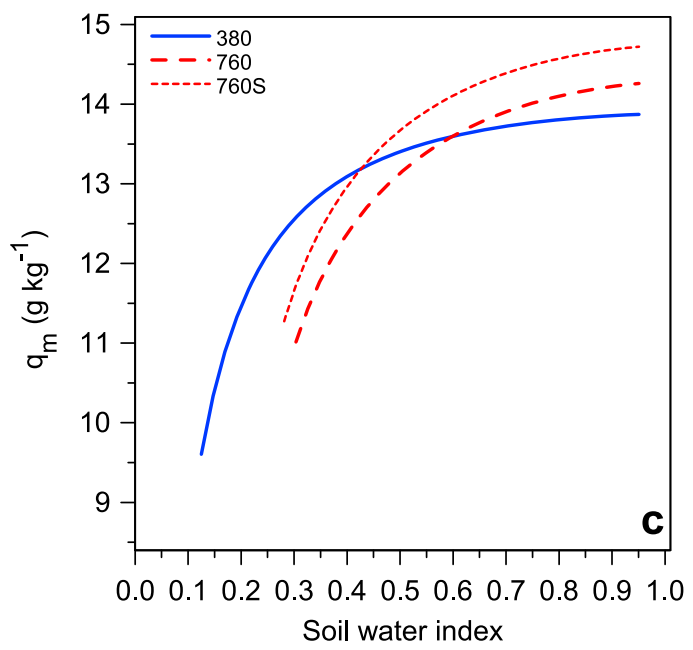

Figure 6. Variation with soil water index of (a) $T_{\mathrm{a}}$ (c) $q_{\mathrm{m}}$, and (d) $\theta_{\mathrm{Em}}$.

[45] The effective cloud albedo, shown in Figure 5b, increases only weakly as SWI increases. However, the exact gradient with soil water is not robust, as it depends on the gradient of $\mathrm{RH}_{\text {mid }}$ we assumed in (22) because cloud varies with $\mathrm{RH}_{\text {mid }}$, as shown in Figure 3a. For the same SWI, the present climate has the most cloud, reaching $25 \%$ over wet soils. The drop in cloud albedo in the warmer doubled $\mathrm{CO}_{2}$ climate is substantial, about $7 \%$. About $5 \%$ of this is related directly to the increase in $\theta_{00}$ (Figure 1c). The rest comes from the cancellation of effects: Falling $\mathrm{RH}_{\text {mid }}$ reduces cloud (Figure 3a), while rising $\mathrm{CO}_{2}$ increases cloud (Figure 2a). However, if the subsidence is also reduced by $10 \%$ in the doubled $\mathrm{CO}_{2}$ climate (case 760S), the drop in cloud albedo becomes small, only $1 \%$.

[46] Figures 5c and 5d show the dependence of the $H$ and $\lambda E$ on SWI for the three scenarios. As SWI decreases, canopy conductance decreases (see Figure 7a later), so that $\lambda E$ decreases and $H$ increases. For the doubling of $\mathrm{CO}_{2}$ with the same subsidence, $H$ increases by $9 \mathrm{Wm}^{-2}$, but $\lambda E$ decreases over dry soils but increases over wet soils because the decrease of cloud increases $R_{\text {net }}$. If we compare the cases 380 and $760 \mathrm{~S}$, which have similar effective cloud albedo, we see the reduction of $\lambda E$ of $-8 \mathrm{Wm}^{-2}$ and increase of $H$ of
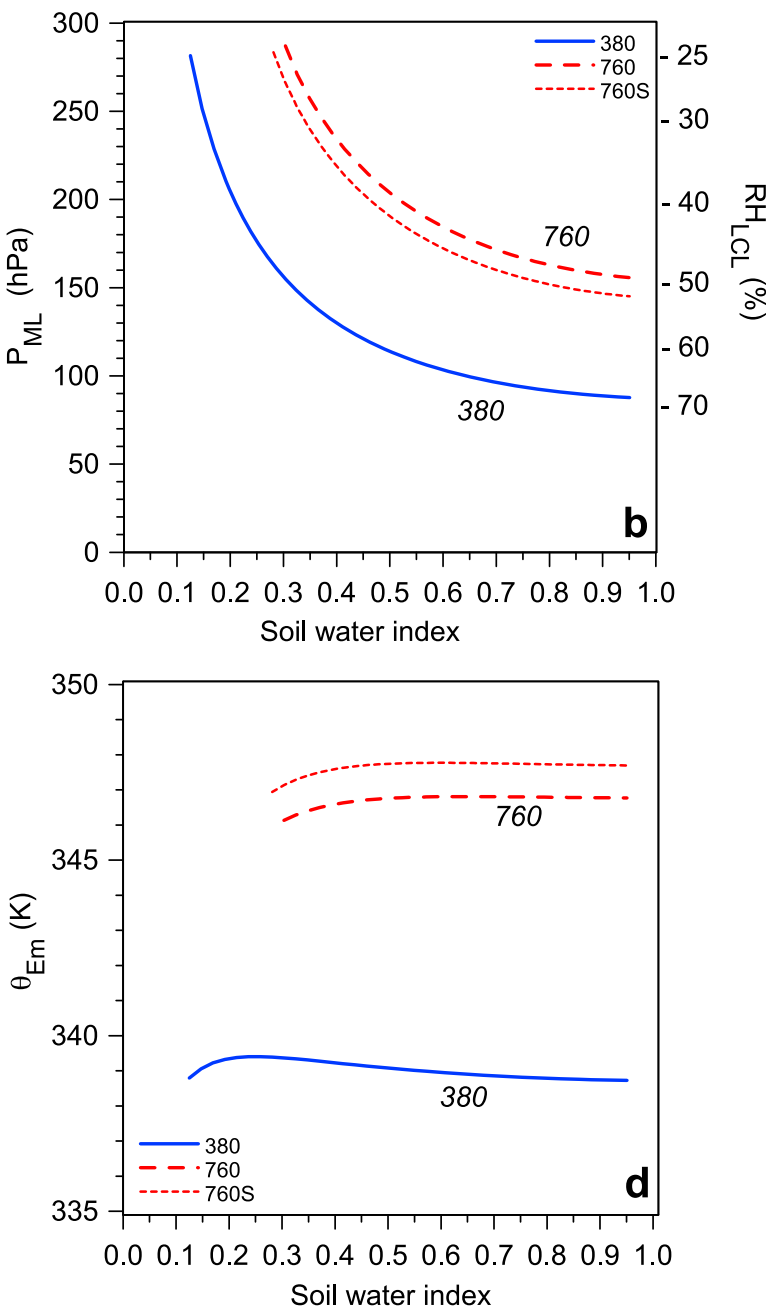

(b) ML pressure thickness and near-surface $\mathrm{RH}$

$+6 \mathrm{Wm}^{-2}$ (for $\mathrm{SWI}>0.3$ ) that is related to the model physiological forcing.

[47] These results from our equilibrium model for a summertime midlatitude undisturbed BL (with its many simplifications and assumptions) are in a general sense qualitatively consistent with Boucher et al. [2009], a transient climate simulation (with fixed vegetation and using the IS92a emission scenario). Their Table 1 gives $\left(-2 \mathrm{Wm}^{-2}\right.$, $\left.+5.4 \mathrm{Wm}^{-2},-2.3 \%\right)$ for the global changes over land of $(\lambda E$, $H$, cloud cover).

[48] Figure 6 shows the equilibrium solutions for $T_{\text {air }}, \mathrm{ML}$ pressure depth and $\mathrm{RH}_{\mathrm{LCL}}, q_{\mathrm{m}}$, and equivalent potential temperature, $\theta_{\mathrm{Em}}$ for the three cases. Figure 6a shows a clear pattern of a warmer equilibrium over dry soils and a general shift to a much warmer equilibrium in a high $\mathrm{CO}_{2}$ climate (6 K warmer for case 760 over moist soils) and slightly less, $5.6 \mathrm{~K}$, for $760 \mathrm{~S}$ with reduced subsidence (as in Figure 2c). Comparing with Figures $1 \mathrm{c}$ and $2 \mathrm{a}$, we see that only about $2 \mathrm{~K}$ of the warming comes from the rise of $\theta_{00}$; most comes from the doubling of $\mathrm{CO}_{2}$.

[49] Figure 6b shows the pressure height of the ML top, $P_{\mathrm{ML}}$, which is the cloud base LCL. $P_{\mathrm{ML}}$ has a systematic increase over drier soils because as canopy conductance decreases (see Figure 7a later), the drop of $\mathrm{RH}$ across the 

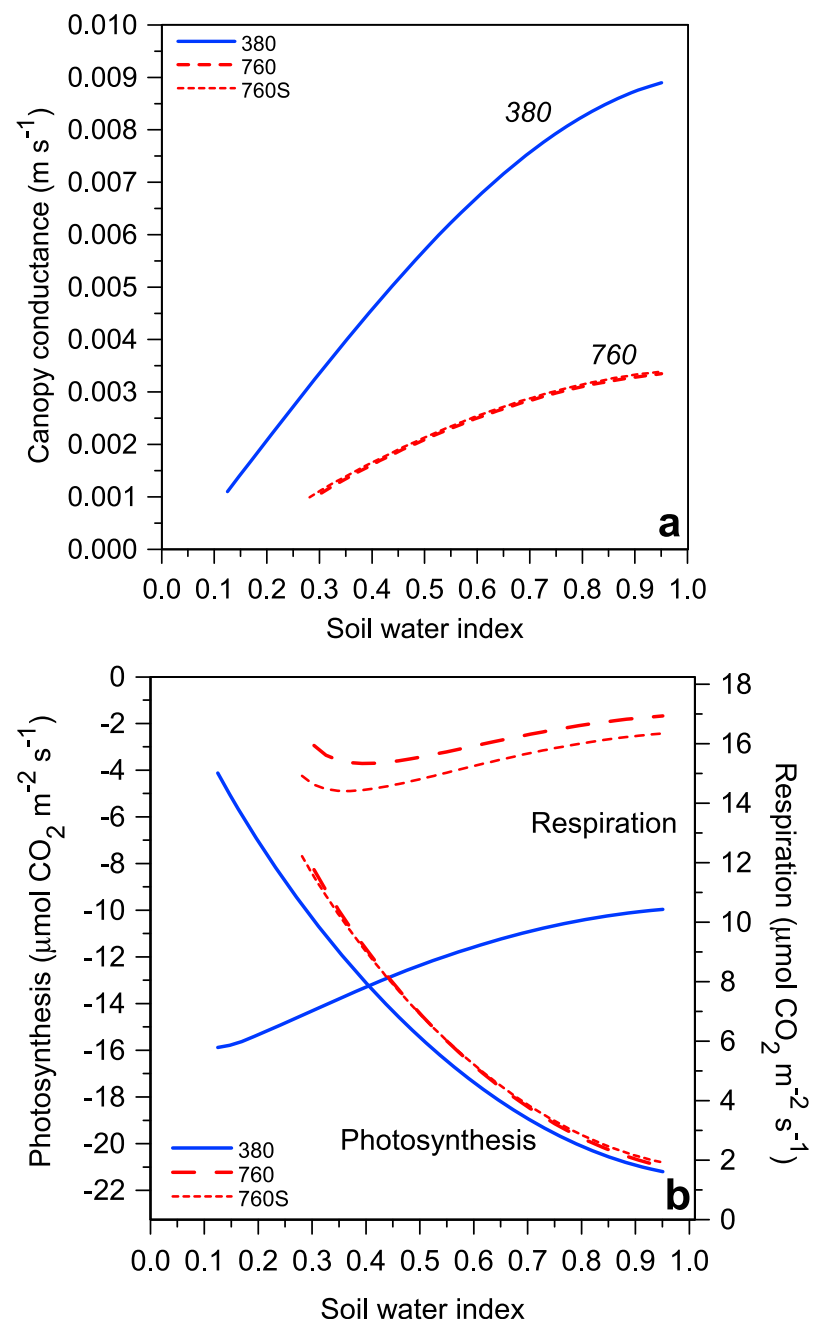

Figure 7. Variation with soil water index of (a) canopy conductance and (b) photosynthetic uptake and respiration.

leaf surface increases [see B2004]. The warmer equilibrium in a high $\mathrm{CO}_{2}$ climate, shown in Figure 6a, leads to deeper MLs. $P_{\mathrm{LCL}}$ is directly related to $T_{\mathrm{air}}, q_{\mathrm{m}}$, and near-surface $\mathrm{RH}_{\mathrm{LCL}}$, which is shown on the right-hand scale with slight approximation. For moist soils (SWI > 0.8), the fall of $\mathrm{RH}_{\mathrm{LCL}}$ in the double $\mathrm{CO}_{2}$ climate is about $19 \%$ for the same subsidence and only $16 \%$ with the reduced subsidence. So for the same SWI, the equilibrium $\mathrm{BL}$ in a doubled $\mathrm{CO}_{2}$ climate is substantially drier and deeper by $59-70 \mathrm{hPa}$ for the two high $\mathrm{CO}_{2}$ cases. Comparing Figures $1 \mathrm{~d}$ and $2 \mathrm{~b}$, we can see that this deepening and drying of the ML is due to the increase of $\mathrm{CO}_{2}$, not the increase in $\theta_{00}$. The reduced subsidence case has a slightly shallower ML (as in Figure $2 \mathrm{~d}$ ). The differences in $q_{\mathrm{m}}$ between the current and future high $\mathrm{CO}_{2}$ climate are rather small. The substantial rise in $T_{\text {air }}$ in the warmer climate gives a large increase in $\theta_{\mathrm{Em}}$, but $\theta_{\mathrm{Em}}$ is relatively flat across all SWI.

[50] The warming of the near-surface air temperature over land in the future high $\mathrm{CO}_{2}$ climate $(5.6-6 \mathrm{~K})$ is a large amplification of the assumed increase of $2 \mathrm{~K}$ in the reference sea surface temperature. This extra warming and the associated deeper drier ML come directly from physiological forcing, the fall of canopy conductance with the rise of $\mathrm{CO}_{2}$.
[51] Our 3.6-4 $\mathrm{K}$ amplification of in the warming of $T_{\text {air }}$ is much larger than the $0.5 \mathrm{~K}$ increase over land that Boucher et al. [2009] ascribe to physiological forcing. This suggests that the behavior of our model with high $\mathrm{CO}_{2}$ may be too extreme, although the comparison is of course not a fair one. Their result comes from a global land mean centennial difference including the full annual cycle and soil water feedbacks, whereas ours is only a summertime midlatitude estimate for the undisturbed BL (with specified soil water) and a highly idealized model, which excludes times of precipitation with direct evaporation of wet soil and canopies and direct evaporation of precipitation into the ML.

[52] Figure 7a shows that canopy conductance, $g_{\mathrm{c}}$ (from (3) a function of photosynthesis, $\mathrm{RH}_{\mathrm{sf}}$, and $\mathrm{CO}_{2 \mathrm{~L}}$ at the leaf), decreases over dry soils and substantially with the doubling of $\mathrm{CO}_{2}$. Note that the change in subsidence has little net effect on $g_{\mathrm{c}}$. The marked drop in canopy conductance with doubled $\mathrm{CO}_{2}$ is the change in the surface coupling that has a profound impact on the ML solutions, giving a deeper, warmer ML with lower near-surface RH. In fact, this decrease of $g_{\mathrm{c}}$ can be thought of as the primary driver of the amplification of the land surface temperature increase. However, the drop of $g_{\mathrm{c}}$ in the doubled $\mathrm{CO}_{2}$ climate in this idealized model with fixed vegetation parameters is about $63 \%$, much larger than the $35 \%$ estimate derived by Sellers et al. [1996] from a global model coupled to the Simple Biosphere model (version 2) and the estimate of a 34\% drop in the study by Douville et al. [2000].

[53] Figure 7b shows photosynthesis and respiration for the three cases. Photosynthetic uptake is only reduced slightly in the future climate scenarios, despite large changes in $\mathrm{CO}_{2}$, the surface equilibrium temperature and $\mathrm{RH}$, and cloud forcing because different terms compensate in the frozen canopy photosynthesis model (not shown). On the other hand, respiration has a large systematic increase with surface temperature. For the present 380 case, photosynthesis exceeds respiration for SWI $>0.19$. However, in the high $\mathrm{CO}_{2}$ climates, this is only true for SWI $>0.54$.

[54] In the doubled $\mathrm{CO}_{2}$ climate, our idealized model gives a large drop of canopy conductance, coupled to a large temperature increase and a large fall of near-surface $\mathrm{RH}$ of order $16 \%-19 \%$. It is likely that our simple vegetation model is too sensitive to the increase of $\mathrm{CO}_{2}$. The vegetation model itself has built-in positive feedback through a quadratic temperature stress function (2), which decreases above an optimum temperature of $26.75^{\circ} \mathrm{C}$, but this only becomes important over dry soils. The lack of a soil water budget in our model is also a severe limitation. Reduced transpiration may increase soil water [Douville et al., 2000; Betts et al., 2007], and this feedback through the soil water budget would reduce the increase in temperature and $\mathrm{ML}$ depth in a high $\mathrm{CO}_{2}$ climate.

[55] A global fall of RH over land and rise of cloud base is the key indicator here. In the past 50 years, global $\mathrm{CO}_{2}$ has increased by about $70 \mathrm{ppm}$ [http://www.esrl.noaa.gov/gmd/ webdata/ccgg/trends/co2_data_mlo.pdf]. Does this mean that a fall of near-surface $\mathrm{RH}$ might soon be measurable? The observations of surface RH trends are few and inconclusive. Vincent et al. [2007] show a small decrease of RH of $0.6 \%$ for Canada for 1953-2003, but the correction of the data for an instrument change is substantial, and the fall of RH was largest in winter and spring. Wang and Gaffen 

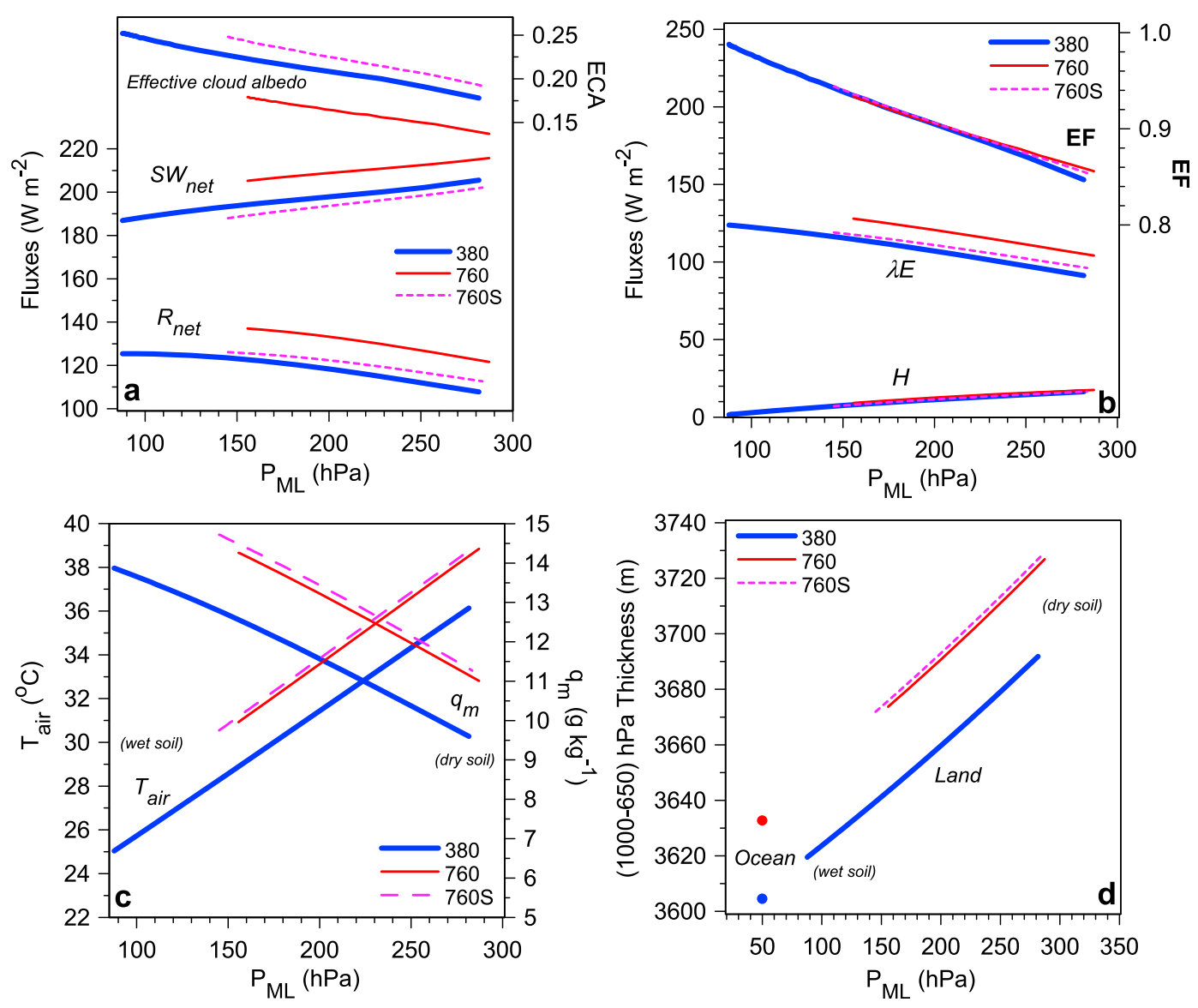

Figure 8. Variation with ML depth of (a) $\mathrm{SW}_{\text {net }}, R_{\text {net }}$, and effective cloud albedo; (b) $\lambda E, H$, and EF (c) $T_{\text {air }}$ and $q_{\mathrm{m}}$, and (d) $1000-650 \mathrm{hPa}$ thickness for oceans and land.

[2001] show similar small decreases over China, but these are largest in winter and at night. Gaffen and Ross [1999] however show evidence of small increases in RH over the United States in winter and spring.

\subsection{Dependence on ML Depth}

[56] B2004 showed that the remapping of the model structure and fluxes in terms of the equilibrium ML depth is a useful simplifying transformation. It replaces the explicit dependence on soil water, which is difficult to measure on regional scales (and whose changes are uncertain in a warmer high $\mathrm{CO}_{2}$ climate) with $\mathrm{ML}$ depth, which is easier to observe and closely related to both cloud base and nearsurface RH. It is particularly useful for our solutions because we have parameterized the LW fluxes and ML cooling in terms of $P_{\mathrm{ML}}$ and ECA.

[57] Figure 8a shows $\mathrm{SW}_{\text {net }}, R_{\text {net }}$, and ECA as a function of $P_{\mathrm{ML}}$. The changes in cloud directly determine the changes in $\mathrm{SW}_{\text {net }}$ and $R_{\text {net }}$ through the equations in section 4.1. But as noted in the previous section, the decrease of $R_{\text {net }}$, shown in Figure 4, comes from the strong dependence on $P_{\mathrm{ML}}$ in $\left(5^{\prime}\right)$.

[58] Figure 8b shows sensible heat flux $H$ has a quasilinear increase with $P_{\mathrm{ML}}$ coming from (18), while $\lambda E$ decreases, with a more visible dependence on changes in cloud. Remarkably, evaporative fraction (EF) plotted on the right-hand scale simply decreases monotonically with ML depth, almost independently of $\mathrm{CO}_{2}$, cloud, subsidence, and $\theta_{00}$. This is an important simplification. For the same $\mathrm{SW}_{\text {net }}$ (clear), equilibrium $\mathrm{EF}$ and $\mathrm{ML}$ depth are almost uniquely related, independent of background forcing climate and canopy conductance. This suggests that may be possible to infer EF for heterogeneous landscapes from ML depth (or from mean near-surface $\mathrm{RH}$, which has a very tight relation to LCL), provided of course that the sweeping assumptions made in constructing this equilibrium model are valid.

[59] Figure 8c shows the increase of $T_{\text {air }}$ and decrease of $q_{\mathrm{m}}$ as the ML gets deeper over drier soils. The three scenarios are distinguished by color, and the high $\mathrm{CO}_{2}$ reduced subsidence case is dashed. The higher $\mathrm{CO}_{2}$ scenarios give a simple shift in temperature and mixing ratio.

[60] Figure $8 \mathrm{~d}$ is the $1000-650 \mathrm{hPa}$ lower tropospheric thickness for the equilibrium land solutions, calculated by linearizing the density profile using three points: the base of the ML, just above the ML, and $650 \mathrm{hPa}$. For comparison, we have added an approximation to the $1000-650 \mathrm{hPa}$ thickness for the two ocean climate references, assuming these have a mixed layer from 1000 to $950 \mathrm{hPa}$, and above $950 \mathrm{hPa}$ follow the same linearized moist adiabat given by (16). Because the temperature profile is identical above the ML, the increase of thickness with $P_{\mathrm{ML}}$ over land depends primarily on the increase of temperature shown in Figure 8c, modified slightly by the decrease of $q_{\mathrm{m}}$ that reduces the virtual temperature. 
[61] The vertical separation between low and high $\mathrm{CO}_{2}$ scenarios is dominated by the $2 \mathrm{~K}$ difference in reference temperature $\theta_{00}$, as seen for the ocean thickness points. The upward shift to the right with doubled $\mathrm{CO}_{2}$ comes from the drop of canopy conductance, which increases $T_{\text {air }}$ and $P_{\mathrm{ML}}$ for the same soil water and lowers $\mathrm{RH}_{\mathrm{LCL}}$. Figure $8 \mathrm{~d}$ highlights the fundamental asymmetry between land and ocean: The reduction of transpiration over land by physiological forcing in a higher $\mathrm{CO}_{2}$ climate impacts ML structure, whereas ML structure change little over the ocean, despite an increase of evaporation in a warmer climate [Betts and Ridgway, 1989]. One possible impact is on the monsoon circulations, which are driven by land ocean contrasts.

\section{Discussion and Conclusions}

[62] We have presented a highly idealized equilibrium model for the undisturbed BL over land to provide a framework for exploring the coupling between the surface, the ML, BL clouds and the SW and LW radiation fields; and between the energy, water, and carbon cycles. We have shown sensitivity studies to varying external parameters and the sensitivity of $\mathrm{BL}$ equilibrium to a warmer doubled $\mathrm{CO}_{2}$ climate.

[63] Sensitivity studies show the dependence on clear-sky $\mathrm{SW}_{\text {net }}$, midtropospheric temperature and humidity, midtropospheric $\mathrm{CO}_{2}$, and subsidence. BL cloud albedo increases by about $20 \%$ with a $20 \%$ increase in $\mathrm{SW}_{\text {net }}$ (clear) and decreases by $22 \%$ with an $8 \mathrm{~K}$ increase in background reference temperature, whereas for both, ML depth changes little. Doubling $\mathrm{CO}_{2}$ reduces stomatal conductance, which gives a warmer, drier, and deeper ML, but BL cloud increases. Increased subsidence gives a drier, deeper equilibrium ML with much less BL cloud. Increasing midtropospheric $\mathrm{RH}$ increases cloud cover and gives a slightly cooler, moister, and shallower ML. For this case, part of the changes in cloud cover and EF come from the LW feedback from the tropospheric water vapor changes.

[64] The impacts of changing subsidence or midtropospheric RH seem intuitive, but the opposite response of BL cloud to increasing clear-sky $\mathrm{SW}_{\text {net }}$ and midtropospheric temperature were surprising. This response illustrates both the power and limitation of the equilibrium constraint. We are assuming a tightly coupled equilibrium system. The constraint on the sensible heat flux dependence on $\mathrm{ML}_{\text {cool }}$ and $P_{\mathrm{ML}}$ couples $R_{\text {net }}$ and $\lambda E$ more tightly, and together with the important cloud forcing terms and the dependence of $P_{\mathrm{ML}}$ on ML temperature and humidity, this constrains the effective cloud albedo.

[65] The three climate change solutions are shown first as a function of soil water index because the model for the undisturbed $\mathrm{BL}$ is missing all the processes associated with precipitation that contribute to the land surface hydrology. In the future climate for the same soil water index, the doubling of $\mathrm{CO}_{2}$ decreases the canopy conductance, which reduces transpiration and increases the surface sensible heat flux, giving a much warmer and deeper ML with a lower surface $\mathrm{RH}$. A $2 \mathrm{~K}$ increase in our ocean reference temperature is amplified over land to a $5.6-6 \mathrm{~K}$ increase in nearsurface temperature. There is a corresponding drop of $\mathrm{RH}$ at the base of the ML of about $16 \%-19 \%$, and a $59-70 \mathrm{hPa}$ rise of cloud base. This process, known as physiological forcing, is one of the primary causes for the amplification of the equilibrium warming over land in fully coupled climate models. However, the $4 \mathrm{~K}$ temperature amplification and $19 \%$ drop of $\mathrm{RH}_{\mathrm{LCL}}$ coming from our simple vegetation model is probably unrealistically large. (It is far larger than the $0.5 \mathrm{~K}$ increase seen globally over land in climate models [Boucher et al., 2009]). We suggest that as $\mathrm{CO}_{2}$ rises in the atmosphere, the fall of near-surface $\mathrm{RH}$ and rise of cloud base are integrated measures of physiological forcing over the landscape. As well as deepening the $\mathrm{BL}$, increasing $\mathrm{CO}_{2}$ reduces evaporative fraction. Equilibrium cloud, however, is sensitive to temperature, subsidence, and $\mathrm{CO}_{2}$, so changes of mean subsidence will play a critical role in determining changes in cloud cover in a warmer, high $\mathrm{CO}_{2}$ climate.

[66] The remapping of the model structure and fluxes in terms of the equilibrium ML depth is a useful transformation because it removes the explicit dependence on soil water changes and canopy conductance. It is particularly useful for our solutions because we have modeled the LW fluxes and ML cooling in terms of $P_{\mathrm{ML}}$ and effective cloud albedo. Many of the key model solutions have a quasi-linear dependence on $P_{\mathrm{ML}}$. Equilibrium EF and ML depth are almost uniquely related independent of background forcing climate. This could be an important simplification because ML depth is an observable, although it is not straightforward to interpret the equilibrium state of the model with say the observed mean over a diurnal cycle. Nonetheless, this suggests that may be possible to infer $\mathrm{EF}$ for heterogeneous landscapes from ML depth, or from mean near-surface RH, which has a very tight relation to LCL. The shift to deeper warmer BLs in a high $\mathrm{CO}_{2}$ climate increase the thickness of the lower troposphere over land relative to the oceans and highlight the fundamental asymmetry between land and ocean. Transpiration over land decreases in a higher $\mathrm{CO}_{2}$ climate, whereas there is an increase of evaporation over the ocean in a warmer climate [Betts and Ridgway, 1989; Held and Soden, 2008].

[67] We are proposing this simple equilibrium model as a framework for exploring sensitivity to key processes and also for the off-line testing of vegetation models, coupled to a BL with clouds. But many caveats need to be remembered. Our simple vegetation model, with a set of fixed vegetation parameters (LAI, $E_{\mathrm{veg}}, Q_{10}$ ) is unsuited for climate change scenarios. Without a diurnal cycle the important details and differences between daytime and nighttime BLs are being ignored. Moreover, our summertime midlatitude model for the undisturbed BL excludes the cold season and many processes, including periods of direct evaporation of wet soil and wet canopies after precipitation, and the evaporation of falling precipitation. Many of the components of the surface water balance, which we do not model, are likely to change in a warmer climate. Precipitation intensity is expected to increase because of the steep increase of saturation mixing ratio with temperature through the Clausius-Clapeyron relation, and this may increase the runoff ratio. Studies using the Hadley Centre climate model [Betts et al., 2007] project a $6 \%$ increase in continental runoff in a doubled $\mathrm{CO}_{2}$ climate. The evaporation from wet soil and wet canopies would be expected to show a similar increase with the saturation mixing ratio. Soil water might increase because of reduced transpiration. 
[68] But there is a more fundamental issue, which we raise but cannot answer. The impetus for this equilibrium model approach originally came from the tropical marine $\mathrm{BL}$, where the balance between radiative processes, subsidence, and BL fluxes is close [Betts and Ridgway, 1988, 1989]. Over land in the tropics, where horizontal advection is small, this same balance might also be a reasonable approximation, averaged over the diurnal cycle. However, in midlatitudes, both horizontal and vertical advection play important roles in the subsidence regions between precipitation events. Cold advection behind frontal systems can modify the BL for days. Even without cold advection, the undisturbed $\mathrm{BL}$ often warms for days between rain events, which then cool and moisten the surface and BL and replenish soil water [Betts and Ball, 1995]. So it is questionable whether the equilibrium model has any wide validity in the midlatitudes. The low values of $H$ in our solutions, which are directly linked to the low values of $\mathrm{ML}_{\text {cool }}$ (calculated from the radiation model) are low compared to observations of undisturbed BLs in the midlatitudes [Betts and Ball, 1995; A. K. Betts, 2000]. In other words, ML net radiative cooling in midlatitudes, given by Figure 4, is insufficient to balance observed surface heat fluxes, using equation (18). A. K. Betts [2000] suggested that in some mean sense, the evaporation of precipitation into the ML was a significant cooling term in the long-term budget. Another possibility, which we have simply avoided by using the equilibrium assumption, is that with a more detailed and properly coupled cloud layer model, the ML may simply warm up on sequential days, until the next rain event occurs. All these issues need further study.

[69] Acknowledgments. Alan Betts acknowledges support from the National Science Foundation from grant AGS0529797. Christine Chiu is supported by the Office of Science (BER, U.S. Department of Energy, Interagency Agreement DE-FG02-08ER64563) as part of the ARM program.

\section{References}

Andrews, T., P. M. Forster, and J. M. Gregory (2009), A surface energy perspective on climate change, J. Clim., 22, 2557-2570.

Ball, J. T. (1987), An analysis of stomatal conductance, Ph.D. thesis, Biology, 89 pp., Stanford University, Stanford, Calif.

Bakwin, P. S., K. J. Davis, C. Yi, S. C. Wofsy, J. W. Munger, L. Haszpra, and Z. Barcza (2004), Regional carbon dioxide fluxes from mixing ratio data, Tellus, Ser. B, 56, 301-311.

Betts, A. K. (1973), Non-precipitating convection and its parameterization, O. J. R. Meteorol. Soc., 99, 178-196.

Betts, A. K. (1976), Modeling subcloud layer structure and interaction with shallow cumulus layer, J. Atmos. Sci., 33, 2363-2382.

Betts, A. K. (1998), Climate convection feedbacks: Some further issues, Clim. Change, 39, 35-38.

Betts, A. K. (2000), Idealized model for equilibrium boundary layer over land, J. Hydrometeorol., 1, 507-523.

Betts, A. K. (2009), Land-surface-atmosphere coupling in observations and models, J. Adv. Model Earth Syst., 1(4), 18 pp., doi:10.3894/ JAMES.2009.1.4. (http://adv- model-earth-syst.org/index.php/JAMES/ article/view/v1n4/JAMES.2009.1.4)

Betts, A. K., and J. H. Ball (1995), The FIFE surface diurnal cycle climate, J. Geophys. Res., 100, 25,679-25,693.

Betts, A. K., and W. Ridgway (1988), Coupling of the radiative, convective and surface fluxes over the equatorial Pacific, J. Atmos. Sci., 45, 522-536.

Betts, A. K., and W. L. Ridgway (1989), Climatic equilibrium of the atmospheric convective boundary layer over a tropical ocean, J. Atmos. Sci., 46, 2621-2641.

Betts, A. K., B. Helliker, and J. Berry (2004), Coupling between $\mathrm{CO}_{2}$, water vapor, temperature, and radon and their fluxes in an idealized equilibrium boundary layer over land, J. Geophys. Res., 109, D18103, doi:10.1029/2003JD004420.
Betts, A. K., R. Desjardins, and D. Worth (2007), Impact of agriculture, forest and cloud feedback on the surface energy balance in BOREAS, Agric. For. Meteorol., 142, 156-169, doi:10.1016/j.agrformet.2006.08.020

Betts, A. K., M. Köhler, and Y. Zhang (2009), Comparison of river basin hydrometeorology in ERA-Interim and ERA-40 reanalyses with observations, J. Geophys. Res., 114, D02101, doi:10.1029/2008JD010761.

Betts, R. A. (2000), Offset of the potential carbon sink from boreal forestation by decreases in surface albedo, Nature, 408, 187-190.

Betts, R. A., P. M. Cox, S. E. Lee, and F. I. Woodward (1997), Contrasting physiological and structural vegetation feedbacks in climate change simulations, Nature, 387, 796-799.

Betts, R. A., et al. (2007), Projected increase in continental runoff due to plant responses to increasing carbon dioxide, Nature, 448, 1037-1041, doi:10.1038/nature06045.

Boucher, O., A. Jones, and R. A. Betts (2009), Climate response to the physiological impact of carbon dioxide on plants in the Met Office Unified Model HadCM3, Clim. Dyn., 32, 237-249, doi:10.1007/s00382-0080459-6.

Collatz, G. J., J. T. Ball, C. Grivet, and J. A. Berry (1991), Physiological and environmental regulation of stomatal conductance, photosynthesis and transpiration: A model that includes a laminar boundary layer, Agric. For. Meteorol., 54, 107-136.

Davis, K. J., P. S. Bakwin, B. W. Berger, C. Yi, C. Zhao, R. M. Teclaw, and J. G. Isebrands (2003), The annual cycle of $\mathrm{CO}_{2}$ and $\mathrm{H}_{2} \mathrm{O}$ exchange over a northern mixed forest as observed from a very tall tower, Global Change Biol., 9, 1278-1293.

Doutriaux-Boucher, M., M. J. Webb, J. M. Gregory, and O. Boucher (2009), Carbon dioxide induced stomatal closure increases radiative forcing via a rapid reduction in low cloud, Geophys. Res. Lett., 36, L02703, doi:10.1029/2008GL036273.

Douville, H., et al. (2000), Importance of vegetation feedbacks in doubled $\mathrm{CO}_{2}$ climate experiments, J. Geophys. Res., 105, 14,841-14,861, doi:10.1029/1999JD901086.

Gaffen, D. J., and R. J. Ross (1999), Climatology and trends of U.S. surface humidity and temperature, J. Clim., 12, 811-828.

Held, I. M., and B. J. Soden (2008), Robust responses of the hydrological cycle to global warming, J. Clim., 19, 5686-5699.

Helliker, B. R., J. A. Berry, A. K. Betts, P. S. Bakwin, K. J. Davis, A. S. Denning, J. R. Ehleringer, J. B. Miller, M. P. Butler, and D. M. Ricciuto (2004), Estimates of net $\mathrm{CO}_{2}$ flux by application of equilibrium boundary layer concepts to $\mathrm{CO}_{2}$ and water vapor measurements from a tall tower, J. Geophys. Res., 109, D20106, doi:10.1029/2004JD004532.

IPCC (2007), Climate Change 2007-The Physical Science Basis, chap. 11, Working Group I Contribution to the Fourth Assessment Report of the IPCC. Cambridge University Press, ISBN-13: 9780521705967.

Joshi, M., and J. Gregory (2008), Dependence of the land-sea contrast in surface climate response on the nature of the forcing, Geophys. Res. Lett., 35, L24802, doi:10.1029/2008GL036234.

Joshi, M. M., J. M. Gregory, M. J. Webb, D. M. H. Sexton, and T. C. Johns (2008), Mechanisms for the land/sea warming contrast exhibited by simulations of climate change, Clim. Dyn., 30, 455-465, doi:10.1007/s00382007-0306-1.

Le Quéré, et al. (2009), Trends in the sources and sinks of carbon dioxide, Nat. Geosci., doi:10.1038/ngeo689.

Monteith, J. L. (1981), Evaporation and surface temperature, Q. J. R. Meteorol. Soc., 107, 1-27.

Randerson, J., J. Canadell, and R. Jackson (2009), Linking carbon storage in terrestrial ecosystems with other climate forcing agents: A synthesis allowing for effective carbon dioxide stabilization policies. (http://www. globalcarbonproject.org/global/pdf/FullRadiativeForcing_BackgroundPaper. pdf)

Ricchiazzi, P., S. R. Yang, C. Gautier, and D. Sowle (1998), SBDART: A research and teaching software tool for plane-parallel radiative transfer in the Earth's atmosphere, Bull. Am. Meteorol. Soc., 79, 2101-2114.

Sellers, P. J., et al. (1996), Comparison of radiative and physiological effects of doubled atmospheric CO2 on climate, Science, 271, 1402-1406, doi:10.1126/science.271.5254.1402.

Vincent, L. A., W. A. van Wijngaarden, and R. Hopkinson (2007), Surface temperature and humidity trends in Canada for 1953-2005, J. Clim., 20, 5100-5113, doi:10.1175/JCLI4293.1.

Wang, J. X. L., and D. J. Gaffen (2001), Late-twentieth-century climatology and trends of surface humidity and temperature in China, J. Clim., 14, 2833-2845.

A. K. Betts, Atmospheric Research, 58 Hendee Ln., Pittsford, VT 05763 , USA. (akbetts@aol.com)

J. C. Chiu, University of Maryland, Baltimore County, Baltimore, MD 21250, USA. 